\title{
A ADMINISTRAÇÃO ESTRATÉGICA DE PROGRAMAS DE RESPONSABILIDADE SOCIAL EM EMPRESAS MULTINACIONAIS: PERCEPÇÕES DA ALTA DIRETORIA
}

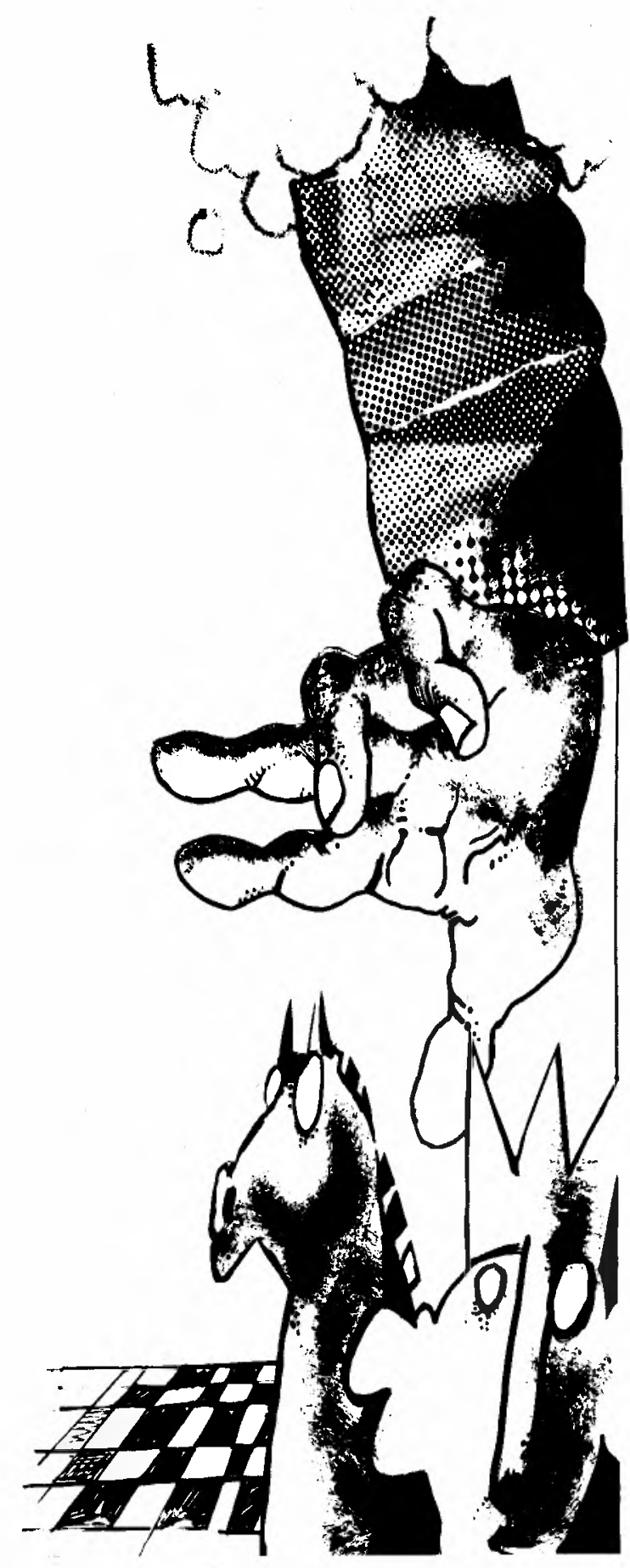

BELMONT F. HAYDEL, Ph.D

Professor associado de Política de Negócios e Meio Ambiente do Rider College, Lawrenceville, N.J., USA.

Tradução de Bloem Business Languages, revisada por Gisela T. Goldenstein. Tabelas traduzidas por Gisela T. Goldenstein.

RESUMO: Esta pesquisa apresenta uma análise da percepção da alta diretoria de multinacionais norteamericanas (MNC's) sobre programas de responsabilidade social de grandes empresas, a partir de um levantamento geral de 18 escritórios de matrizes (29 respondentes) e de um levantamento mais aprofundado, focalizando quatro empresas selecionadas (33 respondentes, 17 dos U.S.A. e 16 do exterior). As empresas constam da listagem da FORTUNE 500; as vendas anuais de cada uma excedem US\$ 1 bilhão; estão nos setores de manufatura, de processo e extrativo. Os dados foram colhidos em 1982-83. O material focaliza o processo de tomada de decisão nas MNCs. Algumas das conclusões principais são: a administração estratégica de programas de responsabilidade social para o pessoal interno das MNCs está ocorrendo, mas sem modelos muito sistemáticos; há recursos empenhados nesses programas, embora um tanto limitados por considerações de custo; tais programas situam-se atrás dos ligados a marketing e produção; ameaças dos ambientes interno externo pressionam por mudanças nos processos de planejamento estratégico, e a maior delas vem dos grupos sindicais e de empregados.

PALAVRAS-CHAVE: administração estratégica, ambiente, empresas multinacionais, planejamento estratégico, programas de responsabilidade social, responsabilidade social, responsabilidade social das grandes empresas.

\section{INTRODUÇÃO}

T ste trabalho apresenta uma análise da perE cepção da alta diretoria de Corporações Multinacionais norte-americanas (MNCs), feita a partir de um levantamento geral em 18 empresas e de um levantamento mais aprofundado em quatro empresas selecionadas, sobre a administração estratégica de responsabilidades sociais. Os dados da pesquisa foram extraídos de um estudo mais amplo, relativo aos públicos internos dessas em- 
presas e a seus requisitos extra-produção, a saber, segurança na fábrica e dos funcionários, educação e recursos humanos e prestação de serviços de saúde, não se limitando, porém, a esses aspectos. Os dados são de natureza empírica, embora a discussão de evidências empíricas esteja relacionada a parte do material das entrevistas.

O material concentra-se no processo de tomada de decisões das MNC's e abrange: (1) o estabelecimento de objetivos/metas, (2) análise ambiental, (3) estratégia e estrutura, (4) implementação e impacto de programas em ambientes fora dos Estados Unidos, e (5) técnicas de avaliação, da maneira como são percebidos pelos executivos das empresas, tanto nas sedes norte-americanas como nas filiais no exterior. A ênfase recai sobre a função de planejamento da administração estratégica. Na seção de resultados, o objetivo é mostrar dados empíricos, movendo-se a apresentação do geral para o particular, sendo que este último representa um enfoque mais abrangente de alguns elementos genéricos do planejamento estratégico da responsabilidade social. Não se tenta comparar a amostra geral com a focalizada (i.é., a amostra do levantamento geral e a do mais aprofundado, respectivamente).

A pesquisa aborda várias questões em nível exploratório acerca das responsabilidades sociais das MNC's, a saber:

1. Métodos sistemáticos para o estabelecimento, implementação e avaliação de objetivos e planos podem estar surgindo.

2. A alta gerência pode perceber um aumento significativo da demanda, por parte do público, no sentido de que as MNC's adotem programas de responsabilidade social.

3. A alta gerência pode estar intensificando sua conscientização da necessidade de programas de responsabilidade social ao responder a ela, ou seja, implementando relevantes programas de ação, que possam afetar e exigir algumas alterações estruturais, inclusive a da avaliação.

4. Pode haver alguma relação entre a lucratividade e a responsabilidade social das MNC's.

5 . Os processos organizacionais de pesquisa, aprendizado e decisão, de acordo com Simon e Cyert-March ${ }^{(1)}$ podem diferir em responsabilidades sociais, em decorrência de tecnologias e do meio-ambiente ${ }^{(2)}$.

Este estudo é por demais limitado para esclarecer essas preocupações de forma abrangente; ao invés disso, os resultados tão somente nos dão algumas indicações acerca dessas preocupações. Em número de cinco, tais preocupações não deverão ser consideradas como posições estanques (discretas) em cenários de estratégias organizacionais mas, sim, ser convenientemente rotuladas neste trabalho, para facilitar a preparação de seu estudo. Portanto, as informações relacionadas a essas preocupações encontram-se contidas nas cinco categorias tratadas na seção de resultados.

Embora a literatura esteja repleta de diferentes conceitos de responsabilidade social, na condução desta pesquisa deu-se (direta ou indiretamente) aos participantes das empresas e aos entrevistados um modelo de responsabilidade social, que incorpora conceitos distintos com relação a papéis sociais e econômicos integrados ou sobrepostos, papéis nos quais as atividades da empresa possam resultar em posições lucrativas e de responsabilidade social, coincidindo, em especial, com as posições de Drucker e de Carrol ${ }^{(3)}$. Existe um enfoque decisivo de, através de planos organizados e sistemáticos, investir os recursos da empresa a fim de aumentar o bem-estar dos públicos interno e externo. A definição de Haydel (4) de responsabilidade social, conforme foi usada nesse estudo, considera a preocupação dos negócios/empresas, em especial das MNCs, de desenvolver e implementar planos de ação voltados ao bem-estar de determinados elementos da sociedade, visando não a combater os intuitos lucrativos, mas sim a dar conta de um papel/missão maior e mais amplo para as empresas atuais.

A metodologia da pesquisa coincide com a abordagem predominante da área, i.e., de estudos de campo de profundidade limitada, exceto pelo fato de que a pesquisa se concentrou na responsabilidade social de empresas multinacionais. Este estudo representa um possível modelo que talvez venha a ser útil em estudos de campo longitudinais e mais amplos. Muito embora consista basicamente de dados empíricos, contém algum material descritivo nas seções de discussão e conclusão.

1. SIMON, Herbert A. Administrative Behavior - A Study of Decision-Making Processes in Administrative Organization. New York, The Free Press, 1945; e CYERT, R.M. \& MARCH, J.G. A Behavioral Theory of the Firm. Englewood Cliffs, New Jersey, Prentice-Hall, Inc., 1963.

2. THOMPSON, James D. Organizations in Action. New York, McGraw-Hill, Inc., 1967.

3. DRUCKER, Peter F. The Practice of Management. New York, Harper \& Brothers, 1954; e CARROL, Archie B. "Social Responsibility as an Objective of Business: Evolving Toward a Model of Corporate Social Performance". In. GLUECK, William E. Business Policy and Strategic Management, 3a. edição, New York, 1980, pp. 62-70.

4. HAYDEL, Belmont F. Jr. Strategic Management and the Effectiveness of Selected Social Responsibility Programs in Selected Multinational Corporations - Empirical and Case Approach, with Perceptions of Top Management. Tese de doutorado apresentada à North Texas State University, 1983. 


\section{LITERATURA RELEVANTE}

Embora pareça ser escassa a literatura sobre a conceituação e o desenvolvimento de aplicações para processos de administração estratégica, há uma grande quantidade de material sobre partes específicas de tais processos. Algumas partes pertinentes de modelos de administração estratégica relacionados ao conteúdo deste trabalho serão passadas em revista a seguir:

Em princípio, modelos tais como os de Glueck, Ansoff, Ackoff, Harrison, Preston, Harvey, Steiner e Murray ${ }^{(5)}$, entre outros, sugerem processos normativos para as empresas em geral. Poucos modelos se relacionam especificamente a fenômenos de negócios internacionais ou multinacionais: Sethi, Clee, Steiner e Cannon, Sethi e Hogle, Schwendiman, Robok et alii ${ }^{(6)}$. Muito poucos modelos de processos consideram a interposição da responsabilidade social nas MNCs, tais como os de Carrol, Gladwin e Walter, Adizes e Weston, e Haydel (7). A maioria dos autores acima citados, contudo, permite inferir, quando não indica expressamente o contrário em seus modelos, considerações sobre reações sociais juntamente com as respostas econômicas dos negócios tradicionais.

Como já foi dito, as partes pertinentes dos processos de administração estratégica examinadas neste trabalho são: a determinação de objetivos/metas, alterações do meio ambiente e suas influências, estratégia e estrutura (com ênfase nas complexidades internas das MNC's), implementação e impacto da responsabilidade social, e técnicas de avaliação de programas de responsabilidade social.

\section{Determinação de objetivos/metas}

Como os termos objetivos e metas são intercambiáveis, neste trabalho eles terão simplesmente o significado de fins ou resultados esperados. Ambos os conceitos representam projeções prescritas do futuro. Para estabelecer algumas distinções, Ackoff ${ }^{(8)}$ entende que objetivos são estados ou resultados de um comportamento desejado, enquanto que metas são aqueles tipos de objetivos cuja obtenção é desejada dentro de um periodo determinado de tempo coberto por um plano.

Parece haver um forte ponto de vista, segundo o qual nem todos os objetivos ou metas dos negócios são ou devem ser econômicos ou total voltados para o lucro ${ }^{(9)}$. A Comissão de Desenvolvimento Econômico ${ }^{(10)}$ elaborou um pouco mais este ponto, mostrando também expectativas resultantes de metas de responsabilidade social e confirmando a sua adoção pelas empresas. A companhia tem objetivos tanto econômicos quanto sociais; os primeiros visam a otimizar a eficiência da alocação de recursos; e os últimos são o resultado da interação entre os objetivos dos partici-

5. Ver: GLUECK, William E. Business Policy and Strategic Management. New York, McGraw-Hill Book Company, 1972; ANSOFF, H. Igor. Corporate Strategy An Analytical Approach to Business Policy for Growth and Expansion. New York, McGraw-Hill Book Company, 1965; ACKOFF, Russel L. A Concept of Corporate Planning. New York, John Wiley \& Sons, Inc., 1970; HARRISON, E. Frank. The Managerial Decision-Making Process. Boston, Houghton Mifflin Company, 1975; PRESTON Lee F. "Strategy - Structure - Performance: A Framework for Organizational/Environment Analysis". In THORELLI, Hans B. (org.) Strategy + Structure = Performance - The Strategic Planning Imperative. Bloomington, Indiana, 1977, pp. 30-49; HARVEY, Donald F. Business Policy and Strategic Management. Columbus, Ohio, Charles E. Merril Publishing Co., 1982; STEINER, George A. Top Management Planning. New York, The Macmillan Publishing Co., Inc., 1969; MURRAY, John A. "Toward a Contingency Model of Strategic Decision". In: International Studies of Management and Org anizations. Vol. 8, no. 4, Winter, 1978, pp. 7-34.

6. Ver: SETHI, Narendra K. “Strategic Planning System for Multinational Companies". In: Long Range Planning. Vol. 15, no. 3, 1982, pp. 80-89; CLEE, Gilbert H. "Organizing for Multinational Planning". In: STEINER, George A. \& CANNON, William M. (orgs.) Multinational Corporate Planning. New York, Macmillan Publishing Company, Inc., 1966, p. 25-46; STEINER, George A. \& CANNON, William M. Op. cit.; SETHI, S. Prakash \& HOGLE, John. "A Conceptual and Operational Framework for Developing the Long-Range Planning Process". In: Journal of International Business Studies. Vol. 4, no. 2, Faal 1973, pp. 31-50; SCHWENDIMANN, John S. Strategic and Long Range Planning in the International Firm. Tese de doutorado apresentada ao Massachusetts Institute of Technology, 1971; ROBOCK, Stefan H.; SIMMONDS, Kenneth \& ZWICK, Jack. International Business and Multinational Enterprises. Homewood, Illinois, Richard D. Irwin, Inc., 1973.

7. CARROL, Archie B. Op. cit.; GLADWIN, Thomas N. \& WALTER, Ingo. "Multinational Enterprise, Social Responsiveness, and Pollution Control". In: Journal of International Business Studies. Vol. 7, no. 2, Fall/Winter 1976, pp. 54-74; ADIZES, Ichak \& WESTON, J. Fred. "Comparative Models of Social Responsibility". Academy of Management Journal. Vol. 16, no. 1, March 1973, pp. 112-128; HAYDEL, Belmont F. Op. cit.

\section{ACKOFF, Russell L. Op. cit.}

9. DRUCKER, Peter F. Op. cit.; CYERT, R. M. \& MARCH, J.G. Op. cit.; SIMON, Herbert A. "On the Concept of Organizational Goals". In: Administrative Science Quarterly. Vol. 9, no. 1, June 1964, pp. 1-22.

10. COMMITTEE FOR ECONOMIC DEVELOPMENT. Social Responsibilities of Business Corporations. A Statement on National Policy by the Policy Committee of the Committee for Economic Development. New York, June 1971. 
pantes da companhia (11). Ansoff parece concordar com a ruptura de Drucker ${ }^{(12)} \mathrm{em}$ relação à tradicional idéia da busca da maximização do lucro e com a proposição deste último, segundo a qual o que a empresa mais persegue é a sobrevivência, através dos objetivos de sobrevivência, ancorados em funções de sobrevivência. Mais ainda, Drucker ${ }^{(13)}$ sustenta que a concepção errônea sobre o lucro e a enraizada hostilidade em relação a ele (por parte dos ativistas sociais) são responsáveis, em grande medida, pelo prevalecimento de pontos de vista segundo os quais existe uma contradição entre o lucro e a capacidade de uma empresa de fazer uma contribuição social. Este trabalho não contempla a discussão desta última questão ${ }^{(14)}$, mas assume o papel social da empresa em relação a seus públicos interno e externo.

Os objetivos de lucratividade nas multinacionais são freqüentemente considerados em diferentes termos, dependendo da natureza da empresa e de sua localização geográfica ${ }^{(15)}$. Por exemplo, Steiner e Cannon dizem que nas MNCs norte-americanas visa-se à "obtenção de lucros", enquanto que nas firmas européias o objetivo fundamental é fazer o melhor uso possível dos recursos. As MNCs reconhecem como importantes os objetivos de responsabilidade social, embora não os tenham necessariamente entre as prioridades máximas ${ }^{(16)}$. Naturalmente, a realização de objetivos de responsabilidade social é uma tarefa mais complexa para as MNCs do que para as companhias nacionais ${ }^{(17)}$. Geralmente, quanto maior é a empresa, mais é exigido dela nos programas de responsabilidade social ${ }^{(18)}$.

\section{Mudanças e influências ambientais}

O trabalho abrangente de Gladwin e Walter ${ }^{(19)}$ mostra os problemas e desafios enfrentados pelas MNCs com referência a questões ambientais e às relevantes modificações atuais da política.

Vários autores, tais como Gladwin e Walter, Boddewyn, McGrath, Hargreaves e Davman, Ackerman e Bauer, Lawrence e Lorsch, Khand- walla, McGreevy, Fahey et alii, Preston (20), entre outros, discutem como as MNCs sobrevivem em

\section{ANSOFF, H. Igor. Op. cit.}

12. DRUCKER, Peter F. Op. cit.

13. DRUCKER, Peter F. Management: Tasks - Responsibilities - Practices. New York. Harper \& Row, Inc. 1973.

14. DAVIS, Keith. "The Case For and Against Business Assumptions of Social Responsibilities". In: Academy of Management Journal. Vol. 16, no. 2, June 1973, pp. 312-322; FRIEDMAN, Milton. "The Social Responsibility of Business is to Increase its Profits". In: The New York Times Magazine. September 13, 1970, pp. 122-126 (p. 13).

15. STEINER, George A. \& CANNON, William M. Op. cit.

16. STEINER, George A. Op. cit.

17. Ver: STEINER, George A. \& CANNON, William M. Op. cit.; STEINER, George A. Op. cit.; GLADWIN, Thomas N. \& WALTER, Ingo. Multinationals Under Fire Lessons in the Management of Conflict. New York, John Wiley \& Sons, 1980; CHAMBERLAIN, Neil W. The Limits of Corporate Responsibility. New York, Basic Books, Inc., 1975; BLAKE, David H. \& DRISCOLL, Robert E. The Social and Economic Impacts of Transnational Corporations: Case Studies of the U.S. Paper Industry in Brazil. New York, Fund for Multinational Management Education, 1977.

18. STEINER, George A. \& CANNON William M. Op. cit.

19. GLADWIN, Thomas N. \& WALTER, Ingo. Multinationals Under Fire - Lessons in the Management of Conflict. Op. cit.

20. GLADWIN, Thomas N. \& WALTER, Ingo. "Multinational Enterprise, Social Responsiveness, and Pollution Control". Op. cit.; GLADWIN, Thomas N. \& WALTER, Ingo. Multinationals Under Fire - Lessons in the Management of Conflict. Op. cit.; BODDEWYN, Jean J. (org.) Corporate External Affairs. Blueprint for Survival. A Business International European Research Report. New York, Business International, 1975; McGRATH, Phyllis S. Managing Corporate External Relations' Changing Perspectives and Responses. New York, Conference Board, 1976; HARGREAVES, John \& DAVMAN, Jan. Business Survival and Social Change. New York, Halsted-Wiley Co., 1975; ACKERMAN, Robert W. \& BAUER, Raymond A. Corporate Social Responsiveness: The Modern

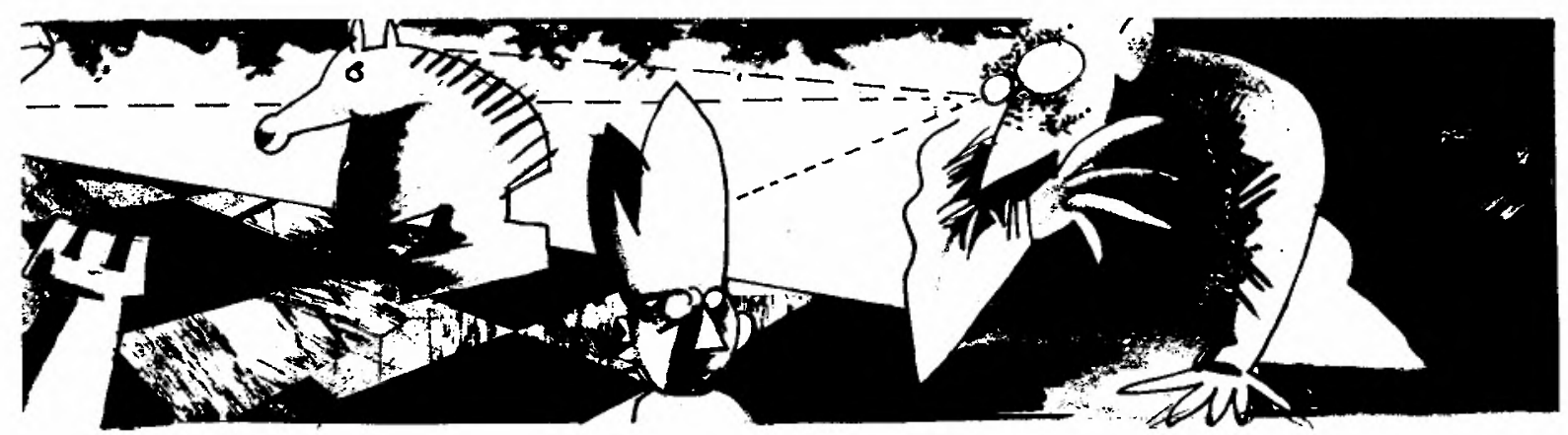


seu meio ambiente e as influências que exercem na sociedade, bem como as questões que causam impacto nas MNCs.

Fahey et alii ${ }^{(21)}$ dizem que tanto os estudiosos como os administradores profissionais estão aceitando a importância do planejamento estratégico como atividade principal organizacional. Partindo-se do ponto de vista de que as organizações são sistemas abertos ${ }^{(22)}$, há uma necessidade cada vez maior de se fazer um exame detalhado, ou melhor, um esquadrinhamento do meio ambiente ${ }^{(23)}$. A incerteza e a turbulência ambientais não só são fatos na vida das multinacionais, como devem ser tratados realisticamente e de modo sistemático ${ }^{(24)}$. Aparentemente, não há um acordo, entre os profissionais "conscientizados", sobre as formas organizacionais adequadas para se conduzirem um esquadrinhamento e estudos futurísticos nem sobre metodologias usadas para o esquadrinhamento ${ }^{(25)}$.

$\mathrm{O}$ esquadrinhamento nas $\mathrm{MNCs}$, em especial para os programas de responsabilidade social, parece ser mais operacional nos escritórios do exterior ${ }^{(26)}$, embora algumas MNCs muito responsáveis possam designar certas suborganizações para programarem e complementarem o esquadrinhamento de programas sociais do ponto de vista da política da empresa-matriz ${ }^{(27)}$. As MNCs enfrentam maiores problemas na realização de suas operações de esquadrinhamento por causa de sua complexidade interna e da postura multifacetada de seus ambientes externos, no que se refere a questões tais como nacionalização e desapropriações, sabotagem e seqüestros, consumismo, inquietude dos trabalhadores, tortura, assassinatos, responsabilidade social, controles de câmbio, impostos etc. ${ }^{(28)}$. Por outro lado, uma revisão dos requisitos para programas internos de responsabilidade social, ou seja, saúde, educação e segurança dos empregados, pode ser encontrada nas operações das multinacionais ${ }^{(29)}$.

\section{Estratégia e estrutura}

O trabalho de Chandler ${ }^{(30)}$, demonstrando basicamente que a estrutura segue a estratégia, não é refutado no que concerne aos negócios das MNCs, embora alguns teóricos acreditem que a formação e a manutenção da estrutura sejam pontos mais complicados nas $\mathrm{MNCs}{ }^{(31)}$. A maioria dos fatores que tende a restringir as estruturas organizacionais pode ser encontrada tanto nas matrizes nacionais, como no exterior, com a diferença de que eles são mais pronunciados e complexos nas subsidiárias e nos escritórios regionais no exterior. Esses fatores podem incluir condições tais como descentralização versus centralização, redes de comunicação etc.

Dilemma. Reston, Virginia, Reston Publishing Co., 1975; LAWRENCE, Paul \& LORSCH, Jay W. Organizations and Environment: Managing Differentiation and Integration. Homewood, Illinois, Richard D. Irwin Press, 1967; KHANDWALLA, P.N. "Environment and Its Impact on the Organizations". In: International Studies of Management and Organization. Vol. II, no. 3, Fall 1972, pp. 297313; MCGREEVY, Edgard R. Some Effects of Environmental Changes on Strategic Planning of U.S. - based Industrial Multinational Corporations. Tese de doutorado apresentada à University of Arkansas, 1978; FAHEY, Liam; KING, William R. \& NARAYANAN, Vadake K. "Environmental Scanning and Forecasting in Strategic Planning - The State of The Art". In: Long-Range Planning. Vol. 14, February 1981, pp. 32-39; PRESTON, Lee E. Op. cit.

21. FAHEY, Liam; KING, William R. \& NARAYANAN, Vadake K. Op. cit.

22. SCHODERBEK, Peter P; KEFALAS, Asterios G. \& SCHODERBEK, Charles G. Management Systems Conceptual Considerations. Dallas, Business Publications, Inc., 1975; KAST, Fremont E. \& ROSENZWEIG, James E. Organization and Management - A Systems and Contingency Approach. 3a. edição, New York, McGraw-Hill Book Co., 1979.

23. FAHEY, Liam; KING, William R. \& NARAYANAN, Vadake K. Op. cit.

24. MILES, Robert H. Macro Organizational Behavior. Santa Mônica, Califórnia, Goodyear Publishing Co., Inc., 1980; THOMPSON, James D. Op. cit.; FAHEY, Liam et alii. Op. cit.

\section{FAHEY, Liam et alii. Op. cit.}

26. GLADWIN, Thomas N. \& WALTER, Ingo. Multinationals Under Fire - Lessons in the Management of Conflict. Op. cit.; BODDEWYN, Jean J. "External Affairs Roles in U.S. Multinational Operating in Western Europe" In: International Studies of Management Organization. Vol. II, nos. 1-2, Spring/Summer 1976, pp. 185-203; HAYDEL, Belmont F.; Jr. Op. cit.; SETHI, S. Prakash \& HOGLE, John. Op. cit.

27. HAYDEL, Blemont F., Jr. Op. cit.; KLEIN, Philip A. The Social Responsibilities of Business". In: STEINER, George A. \& CANNON, William M. (orgs.) Op. cit., pp. 271-282.

28. FAYERWEATHER, John. International Business Management; A Conceptual Framework. New York, McGraw-Hill Book Company, 1969; GLADWIN, Thomas N. \& WALTER, Ingo. Multinationals Under Fire - Lessons in the Management of Conflict. Op. cit.; BODDEWYN, Jean J.Corporate External Affairs: blueprint for Survival. Op. cit.

29. HAYDEL, Belmont F. Op. cit.

30. CHANDLER, Alfred E. Strategy and Structure . Cambridge, Massachusetts, Massachusetts Institute of Techonology Press, 1962.

31. STOPFORD, John M. \& WELLS, Louis T., Jr. Managing the Multinational Enterprise - Organization of 
Entretanto, Stopford \& Wells e Davis ${ }^{(32)}$ mostram que as estruturas básicas das empresas, principalmente as relativas a produto, região geográfica e funções, também prevalecem nas MNCs, embora, por sua própria natureza, as MNCs também separem suas divisões em internacionais, mundiais ou estruturas mistas. Mesmo assim, Davis ${ }^{(33)}$ sugere que as necessidades de especialização e coordenação são vistas como inversamente relacionadas. Por esse motivo as MNCs tendem a achar mais difícil coordenar unidades diferenciadas, à medida que se tornam mais especializadas ${ }^{(34)}$.

Segundo Franko e Davis ${ }^{(35)}$, a escolha da premissa que deve ser considerada a mais importante na divisão de unidades das MNCs é ditada, em grande parte, pelas necessidades estratégicas. $\mathrm{O}$ fenômeno que surge do antagonismo e da tensão entre a necessidade de especialização e a de coordenação pode ser compreendido e encontrado na prática em estruturas multidivisionais.

A diversificação nas estruturas de MNCs foi adotada por empresas européias, derivando de estratégias que remontam aos anos $50^{(36)}$. Embora diferentes tecnologias possam ditar estruturas organizacionais, conforme demonstram Woodward e Burns \& Stalker ${ }^{(37)}$, há pouca evidência documentada ${ }^{(38)}$ de mudanças estruturais devidas a programas de responsabilidade social, exceto a que pode ser encontrada em programas específicos de desenvolvimento social, tais como os de segurança de empregados e de fábrica em empresas multinacionais ${ }^{(39)}$.

\section{Implementação e impacto das responsabilidades sociais}

As áreas de implementação e de impacto (ou eficácia) da responsabilidade social são duas questões distintas, embora sejam discutidas juntamente aqui, dada a relação de causa e efeito existente entre elas. A implementação da responsabilidade social das MNCs parece ser uma das áreas mais fracas do processo de administração estratégica ${ }^{(40)}$, talvez devido à alocação imprópria de recursos e ao acompanhamento inadequado dos compromissos e das políticas, programas e instruçōes recorrentes ${ }^{(41)}$.

Bauer, por outro lado, reuniu a identificação das questões de responsabilidade social, o compromisso e a implementação. Suas conclusões mostram que tanto os homens de negócios como os estudiosos dão maior ênfase à identificação e ao compromisso, salientando ser desejável detectar logo as questões sociais. Um modelo eficaz de resposta da empresa começa com um processo que envolve conscientização das questões, compromisso em relação às respostas a elas e a sua implementação em si, de acordo com Ackerman \& Bauer, Preston \& Post, e Votaw \& Sethi ${ }^{(42)}$.

Post argumentou que o processo de analisar uma firma confrontada com muitas questões sociais é monumental, o que parece aplicar-se mais a

the Firm and Ownership of the Subsidiaries. New York, Basic Books, Inc., 1972.; FAYERWEATHER, John. Op. cit.; WITTE, Eberhard. "Field Research on Complex Decision-Making Processes". In: International Studies of Management and Organization. Vol. 2, 1972, pp. 156-182; PRESTON, Lee E. Op. cit.

32. STOPFORD, John M. \& WELLS, Louis T., Jr. Op. cit.; DAVIS, Stanley M. Managing and Órganizing Multinational Corporations. New York, Pergamon Press, 1979.

\section{DAVIS, Stanley M. Op. cit.}

\section{Idem, ibidem.}

35. FRANKO, Laurence G. "The Move Toward a Multidivisional Structure in European Organizations". In: Administrative Science Quarterly. Vol. 20, no. 4, December, 1975, pp. 493-506; DAVIS, Stanley M. Op. cit.

36. CHANNON, Derek F. Strategy and Structure of British Enterprise. Cambridge, Massachusetts, Harvard Graduate School of Business Administration, 1973; TANNHEISER, Heins. Strategy and Structure of German Enterprise. Tese de doutorado apresentada à Harvard Graduate School of Business Administration, 1972; PAVAN, Robert K. Strategy and Structure of Italian Enterprise. Tese de doutorado apresentada à Harvard Graduate School of Business Administration, Cambridge, 1972.

37. WOODWARD, Joan. Industrial Organization: Theory and Practice. London, Oxford Press, 1965. BURNS, Tom \& STALKER, G.M. The management of Innovation. London, Tavistock, 1961.

38. BODDEWYN, Jean J. Corporate External Affairs: blueprint for Survival. Op. cit.

39. HAYDEL, BELMONT F., Jr. Op. cit.

40. Idem, ibidem.

41. Idem, ibidem; BAUER, Raymond A.; CAUTHORN, Terry L. \& WARNER, Ranne P. "The Management Process Audit Manual". In: PRESTON, Lee E. (org.) Research in Corporate Social Performance and Policy. Vol. 1, Greenwich, Connecticut, 1978, pp. 265-277; ALDAG, Ramon J. \& BARTOL, Katheryn M. "Empirical Studies of Corporate Social Performance and Policy: A Survey of Problems and Results". In: PRESTON, Lee E. Research in Corporate Social Performance and Policy. Op. cit., pp. 165-199.

42. ACKERMAN, Robert W. \& Bauer,R. A.Op. cit.; BAUER, Raymond A.; CAUTHORN, Terry L. \& WARNER, Ranne P. Op. cit.; PRESTON, Lee E. \& POST, James E. Private Management and Public Policy. Englewood Cliffs, New Jersey, Prentice-Hall, Inc., 1975; VOTAW, D. \& SETHI, S.P. The Corporate Dilemma. Englewood Cliffs, New Jersey, Prentice-Hall, 1973. 
negócios das multinacionais. Neste caso a suposição principal é de que a empresa e a sociedade são sistemas sociais, ou que há necessidade de se compreender a teoria e a análise de sistemas. A organização é intrinsecamente uma parte de seu ambiente total ${ }^{\left({ }^{(4)}\right)}$. Este é necessariamente o caso quando se considera a capacidade de resposta social (44). A responsabilidade social das empresas engloba tanto o pessoal interno da organização como o externo ${ }^{(45)}$. A implementação, portanto, está ligada a uma compreensão da impenetrável perspectiva de sistemas, tanto no nível macro (as relações sociais, em contraste com a divisão convencional dos níveis econômico e jurídico-político) como no nível micro (variáveis que influenciam o desempenho e o comportamento da própria empresa), de acordo com a abordagem conceitual de Post ${ }^{(46)}$.

Os impactos almejados podem, então, ocorrer quando há um desempenho eficaz dos três estágios de resposta descritos por Bauer ${ }^{(47)}$. Os impactos podem ser considerados como resultados.

De acordo com Blake \& Driscol ${ }^{(48)}$, em seu estudo sobre o impacto sócio-econômico da indústria de papel norte-americana no Brasil, as empresas transnacionais penetram profundamente em questões ambientais, tais como estado, poluição, reflorestamento, empregos, política, economia (por exemplo: rendimento monetário pessoal e da empresa, câmbio, salários, impostos) etc. Não só há um interesse em determinar a extensão do impacto, como também a qualidade de vida no trabalho do pessoal da empresa.

Um problema significativo no desempenho social das empresas é a medição do impacto. Intimamente relacionada a esta questão, está a dificuldade que os pesquisadores de desempenho social têm tido com o conceito nebuloso de responsabilidade social, ou com a busca de sua definição ${ }^{(49)}$; muitos, porém, têm tentado definir o termo ${ }^{(51)}$.

A mensuração do impacto torna-se ainda mais complicada por causa de problemas relativos à operacionalização da responsabilidade social. A mensurabilidade do impacto pode parecer mais simples, contudo, ao se avaliarem resultados advindos do pessoal interno da empresa.

\section{Técnicas de avaliação de programas de responsabilidade social}

Apesar da importância óbvia que tem o desempenho da responsabilidade social no crescente contexto da abordagem de sistemas das MNCs, existe relativamente pouca evidência para relacionar a eficiência da companhia a um comporta- mento socialmente responsável, de acordo com Aldag \& Bartol ${ }^{(51)}$. Por outro lado, Reiman ${ }^{(52)}$ encontrou alguma correlação entre as exigências da sociedade $\mathrm{e}$ a atitude favorável de alguns dirigentes para com elementos da sociedade, como, por exemplo, clientes, governos, fornecedores. A satisfação da sociedade estava positivamente relacionada aos níveis de desempenho da empresa. As principais dificuldades em determinar e medir programas de responsabilidade social estão relacionadas às múltiplas variáveis sócio-psicológicas encontradas nas atitudes dos dirigentes face a questões sociais, embora alguns sejam confiavelmente medidos ${ }^{(53)}$.

Apesar das dificuldades, parece haver um acordo entre os estudiosos de que a maioria dos desempenhos deve ser avaliada, sejam as respostas sociais ou econômicas, embora Haydel (54) tenha descoberto, num programa complexo e caro de desenvolvimento social de um grande $\mathrm{MNC}$,

43. KAST, Fremont E. \& ROSENZWEIG, James E. Organization and Management - Systems Approach. New York, McGraw-Hill Book Co., 1970.

44. DAVIS, Keith, Op. cit. cit.

45. ALDAG, Ramon J. \& BARTOL, Kathryn M. Op.

46. POST, James E. "Research on Patterns of Corporate Response to Social Change". IN: PRESTON, Lee E. Research in Corporate Social Performance and Policy. Op. cit., pp. 55-77.

47. BAUER, Raymond A.; CAUTHORN; L. Terry. \& WARNER, Ranne P. Op. cit.

48. BLAKE, David H \& DRISCOLL, Robert E. Op. cit.

49. ALDAG, Ramon J. \& BARTOL, Kathryn M. Op. cit.; SETHI, S. Prakash \& HOGLE, John Op. cit.

50. DAVIS, Keith. Op. cit.; COMMITTEE FOR ECONOMIC DEVELOPMENT. Op. cit.; HAYDEL, Belmont F., Jr. Op. cit.; FRIEDMAN, Milton. Op. cit.; STEINER, George A. \& CANNON; William M. Op. cit.; LUTHANS, Fred; HODGETTS, Richard \& THOMPSON, Kenneth R. Social Issues in Business. 3a. ediçāo. New York, Macmillan Publishing Company, Inc., 1980; STEINER, George A. \& STEINER, John F. Social Policy as Business Policy". In: PRESTON, Lee E. Research in Corporate Social Performance and Policy. Op. cit., pp. 201-221. cit.

51. ALDAG, Ramon J. \& BARTOL, Kathryn M. Op.

52. REIMANN B.C. Organizational Effectiveness and Management's Public Values: A Canonical Analysis". In: Academy of Management Journal. No. 18, 1975, pp. 224 241. cit.

53. ALDAG, Ramon J. \& BARTOL, Kathryn M. Op.

54. HAYDEL, Belmont F., Jr. Op. cit. 
que ela própria fazia pouco trabalho de avaliação, parecendo delegá-lo a grupos externos.

Mesmo assim, Davis ${ }^{(55)}$ sustenta que a própria empresa tem a obrigação de, como parte do seu processo de decisões, determinar os efeitos de suas decisões sobre sistemas sociais externos, para assegurar benefícios sociais juntamente com os tradicionais ganhos econômicos que deseja. Os estudiosos geralmente concordam em que os modelos de planejamento estratégico devem levar em consideração a avaliação por motivos de eficácia ou impacto e para obter feedback ${ }^{(56)}$. O planejamento a longo prazo da responsabilidade social nas MNCs não pode ser eficaz sem avaliação e feedback periódicos, com o uso de técnicas de avaliação aceitáveis.

De acordo com Frederick ${ }^{(57)}$, a auditoria social, ou a medição do desempenho da responsabilidade social da empresa, surgiu como um interesse geral em 1972, "o ano da auditoria social". O Conselho de Prioridades Econômicas ${ }^{(58)}$ informou que nessa ocasião grandes empresas já haviam sido alvo de protestos sociais, que atingiram um amplo espectro (por exemplo: poluição, proteção ao consumidor, protestos de ordem religiosa, racial e sexual, segurança e saúde dos empregados). Portanto, a corporação inteira, levando em consideração todos os impactos sociais que provoca, deveria sofrer uma auditoria e ser considerada responsável.

A comunidade acadêmica tem, naturalmente, enfrentado numerosos problemas de pesquisa, sendo o principal deles a metodologia a ser seguida. Como exemplo, as técnicas de medição têm que ser aperfeiçoadas, os dados sociais têm sido difíceis de obter, benefícios sociais e custos não têm sido precisamente computados e as relações entre os lucros da empresa e as respostas econômicas ainda não foram esclarecidas ${ }^{(59)}$.

As práticas sociais e as teorias dos negócios teriam que ser integradas em um esforço conjunto para definir-se melhor a responsabilidade social das grandes empresas ${ }^{(60)}$.

Desde o começo de 1972, acredita-se ter havido algum progresso na avaliação e na auditoria sociais, porém a extensão desse progresso está ainda para ser documentada. Deve-se ressaltar que as auditorias sociais podem implicar em traços de controle e de esquadrinhamento, isto é, consideração tanto do início como do fim do processo de administração estratégica ${ }^{(61)}$.

\section{A PESQUISA}

\section{Metodologia e limitações}

A pesquisa consistiu de duas amostras, ambas incluindo as percepções dos altos administradores de MNCs norte-americanas. Todas as empresas constavam entre as 500 da Fortune, cada uma com vendas anuais superiores a um bilhão de dólares nos setores de manufatura, processamento e extrativos. A amostra geral (A) foi composta de 20 respondentes de 18 matrizes de empresas; e a amostra focalizada (B), de 33 respondentes (17 de matrizes e 16 de escritórios do exterior) provenientes de quatro empresas selecionadas. $O$ grupo da amostra geral respondeu a um questionário de seis páginas e os grupos da amostra focalizada responderam a questionários de doze e dez páginas respectivamente.

Os três conjuntos de instrumentos de pesquisa examinaram um conteúdo de pesquisa mais amplo do que o coberto por este trabalho, incluindo tópicos demográficos, planejamento e estratégia, estrutura organizacional, implementação e eficácia de programas, e restrições e oportunidades ambientais. Algumas partes relevantes do conjunto maior do material aparecem neste texto. Os dados foram obtidos ao longo dos anos de 1982 e 1983.

55. DAVIS, Keith. Op. cit.

56. CARROLL, Archie B. Op. cit.; GLUECK, William E. Op. cit.; ANSOFF, H. Igor. Op. cit.; RINGBAKK, K.A. "The Corporate-Planning Life Cycle - An International Point of View". In: DAVIS, Stanley M. Managing and Organizing Multinational Corporations. New York, Pergamon Press, 1979, pp. 354-379.

57. FREDERICK, William C. Auditing Corporate Social Performance: The Anatomy of A Social Research Project. In: PRESTON, Lee E. Research in Corporate Social Performance and Policy. Op. cit, pp.123-137.

58. COUNCIL ON ECONOMIC PRIORITIES. "Minding the Corporate Conscience: The 1972 Movement of Corporate Responsibility". In: Economic Priorities Report. March/April, 1972.

59. FREDERICK, William C. Op. cit.

60. BAUER, Raymond A. \& FENN, Dann H., Jr. The Corporate Social Audit. New York, Russel Sage Foundation, 1972; BAUER, Raymond A. \& FENN, Dann H., Jr. "What is a Corporate Social Audit?" In: Harvard Business Review. January/February, 1973, p. 37-48.

61. BLAKE, David H., FREDERICK, William C. \& MYERS, Mildred S. Social Auditing: Evaluating the Impact of Corporate Programs. New York, The Praeger Publishers, Inc, 1976; BÂUER, Raymond A. \& FENN, Dann H., Jr. The Corporate Social Audit. Op. cit.; BAUER, Raymond A. \& FENN, Dann, H., Jr. "What is a Corporate Social Audit?" Op. cit.; HUMBLE, John. The Responsible Multinational Enterprise. London, Foundation for Business Responsibilit, 1975; HUMBLE, John. Social Responsibility Audit: A Management Tool for Survival. New York, Amacom, 1973; BAUER, Raymond A. (org.) Social Indicators. Cambridge, Massachusetts, Massachusetts Institute of Technology, 1966. 
A apresentação da amostra geral visa a mostrar uma generalização de impressões de um grupo de produtores de distintos setores que empregam tecnologias diferentes, incluindo equipamentos e vestuário para esportes, equipamentos de testagem eletrônica, maquinário de processamento de alimentos, produtos de cuidados de saúde, sistemas de ar condicionado, aço para estruturas e outros materiais de construção, motores diesel de alta velocidade, computadores, módulos de circuito, petróleo operacional e cru, pneus e produtos industriais à base de borracha, peças para aeronáutica, produtos petroquímicos e borrachas sintéticas, instrumentos médicos e analíticos eletrônicos, vestuário, processamento químico, perfuração com diamantes, equipamentos para segurança industrial, medicamentos, perfumaria, cosméticos, luminárias, produtos de papel e papelão - sem cobrir todas as linhas de produção das 18 indústrias em questão. Não foram feitas entrevistas pessoais nessas empresas.

A amostra focalizada teve a intenção de cobrir uma percepção mais abrangente do planejamento estratégico, tanto das sedes, como dos escritórios no exterior. Estas quatro empresas consistem de: um produtor de plásticos e processador químico e petroquímico; um produtor de peças e motores para automóveis; um fabricante de produtos farmacêuticos, cirúrgicos e de saúde; e um produtor de remédios com receitas. Além disso, os 17 respondentes de matrizes norte-americanas foram pessoalmente entrevistados pelo pesquisador. As sedes norte-americanas das MNCs ajudaram na seleção de 16 respondentes estrangeiros, localizados em todas as áreas do mundo livre.

Os dados pessoais dos respondentes permitem situá-los na faixa étaria de 40 a 55 anos e acusam uma grande variação nos níveis de experiência e de educação formal. A maioria dos respondentes ocupava seus cargos há menos de cinco anos, embora estivesse na empresa há mais de dez. Todos os respondentes tinham posições relacionadas de alguma forma ao planejamento estratégico e a políticas que envolviam programas de responsabilidade social.

Em ambas as amostras, os respondentes das sedes norte-americanas ocupavam posições tais como: de vice-presidente senior, vice-presidente do desenvolvimento e planejamento da organização, vice-presidente administrativo, conselheiros de relações públicas, vice-presidente para negócios da comunidade, vice-presidente para negócios da empresa, vice-presidente para planejamento e desenvolvimento dos negócios, gerente de ambiente de negócios internacionais, diretor de projetos internacionais, diretor de pesquisas empresariais, diretor de pessoal internacional, diretor de planejamento empresarial, diretor de planejamento econômico, diretor de desenvolvimento de recursos humanos etc. Os 16 respondentes das empresas no exterior ocupavam cargos tais como: diretor do conselho e representante no país, presidente e diretor geral no país, vice-presidente regional de planejamento, diretor regional de planejamento e desenvolvimento, gerente no país de relações de pessoal, coordenador internacional no país, diretor no país de pessoal e de assuntos administrativos etc.

Ambas as amostras, geral e focalizada, são apresentadas como grupos separados, subentendendo-se que havia variações entre as duas, como também, dentro da amostra focalizada, entre os respondentes de sedes norte-americanas e os do exterior. Não se fez nenhuma tentativa neste trabalho de se distinguir as percepções norte-americanas das do exterior, embora os dados individuais, não apresentados neste trabalho, ocasionalmente, demonstrem variações. As tabelas de número 1 a 16 se referem à amostra (A) geral, as de número 17 a 30 , à amostra focalizada (B). Os números entre parênteses que se seguem ao número da tabela correspondem às tabelas da outra amostra, indicando-se, assim, os dados correspondentes em ambas as amostras.

\section{RESULTADOS DA PESQUISA}

O material desta seção expõe as informações obtidas, agrupando-as nas mesmas cinco categorias utilizadas na revisão da literatura relevante (determinação de objetivos e metas, mudanças e influências ambientais, estrutura e estratégia, implementação e impacto da responsabilidade social e técnicas de avaliação de programas de responsabilidade social). Em cada uma dessas cinco categorias, tanto a amostra geral como a focalizada são discutidas. As tabelas se encontram ao final do trabalho e são apresentadas em ordem nem sempre paralela à das cinco categorias, pois constituem parte de um levantamento maior em outra seqüência do desenvolvimento da pesquisa. Os resultados aqui apresentados não cobrem todos os problemas abordados na discussão da literatura relevante. Em lugar disso, algumas questões selecionadas são apresentadas na seção de resultados.

Da mesma forma que na revisão bibliográfica, nesta seção não se dá necessariamente um tratamento equivalente às cinco categorias individuais da mesma questão. Não foi feita nenhuma comparação entre as informações das duas amostras. Alguns resultados de cada uma das trinta tabelas são apresentados. 


\section{Estabelecimento de Objetivos e Metas}

(A) - Amostra Geral:

$\mathrm{Na}$ maioria das vezes, pouca evidência foi encontrada dando apoio ao uso de modelos de gerenciamento estratégico formalmente elaborados, para o estabelecimento de objetivos em programas de responsabilidade social, conquanto alguns métodos tenham sido encontrados em prática (ver tabela 2). $60 \%$ dos participantes indicaram uma ligação de moderada a total, entre o seu planejamento de responsabilidade social e o planejamento estratégico global da corporação, sendo que $80 \%$ deles acreditam que a responsabilidade social da sua empresa é crítica para a obtenção das metas de alcance mundial da corporação (ver tabelas 3 e 4). Na formulação de planos para os programas de responsabilidade social, menos de $50 \%$ relataram que os escritórios centrais consultaram as suas subsidiárias no exterior, variando desde nenhuma consulta a consultas ocasionais (ver tabela 1).

Com relação aos valores da alta administração que afetam o planejamento estratégico, os valores sociais e econômicos foram considerados os de maior relevância* entre as impressões dos respondentes (ver tabela 5).

Os critérios administrativos que mais pesam no desenvolvimento do planejamento estratégico são: experiência gerencial, intuição/capacidade de previsão gerencial, valores gerenciais combinados (sociais, econômicos, estéticos, políticos, religiosos e teóricos) e habilidade gerencial (ver tabela 6).

Com relação à liderança da empresa no planejamento dos itens selecionados de responsabilidade social, os respondentes tenderam a ser unânimes em suas impressões sobre a importância de planos e serviços de saúde para os empregados de suas empresas, bem como a segurança das instalações e dos empregados. Aproximadamente $28 \%$ dos participantes deram o grau de quatro a cinco de importância para essas questões (conforme tabela 8).

\section{(B) - Amostra Focalizada:}

Nas 33 respostas combinadas dos escritórios nacionais e no exterior, com referência ao uso de modelos de administração estratégica formalmente elaborados para o estabelecimento de objetivos de responsabilidade social, predominam as negativas (ver tabela 17).

A relação entre o processo de planejamento da responsabilidade social e o planejamento estra- tégico global da corporação apresenta-se como sendo de moderada a total para aproximadamente $57 \%$ dos participantes (ver tabela 18). No total, $24 \%$ dos participantes acreditam que os objetivos de responsabilidade social de suas firmas individuais são críticos (no grau máximo da escala de importância relativa) para que suas MNCs obtenham sucesso em suas metas globais internacionais (ver tabela 19). Em entrevistas com executivos das matrizes, constatou-se que todos os programas de responsabilidade social estão recebendo mais recursos do que em qualquer momento do passado, no intuito de atingir seus objetivos.

Com referência à maneira pela qual os executivos dessas quatro empresas encaram suas reações às demandas sociais em todo o mundo, somente $6 \%$ dos respondentes indicaram planejamento pré-concebido, ou posições ativas por parte de suas filiais (conforme tabela 20).

\section{Mudanças e influências ambientais}

\section{(A) - Amostra Geral}

De uma maneira ou de outra, todos os grupos de interesse escolhidos, tais como clientes, fornecedores, concorrentes, empregados/sindicatos, governo anfitrião e da matriz, influenciam a determinação pelas companhias dos seus programas de responsabilidade social. Os empregados/sindicatos e os governos da matriz e anfitrião têm o maior peso, e os fornecedores, o menor (ver tabela 7). Quanto à existência de ameaças a suas firmas pelo meio ambiente social/político/cultural, $70 \%$ dos participantes indicaram "algumas vezes", enquanto que apenas $15 \%$ indicaram "sim" (conforme tabela 16).

\section{(B) - Amostra Focalizada}

Os grupos de interesse que exercem maior influência nesta amostra sobre a determinação pelas empresas de seus programas de responsabilidade social são os empregados/sindicatos de trabalhadores, governos anfitriões e concorrentes (conforme tabela 22). De todos os respondentes, $66 \%$ sentem que qualquer incerteza ambiental poderá afetar a regularidade dos lucros, de forma moderada a intensa (ver tabela 29), embora somente $21 \%$ tenham indicado que as forças ambientais so-

* Nota da Redação: As escalas variam de 1 a 5 , e o grau 1 representa sempre o menor impacto, ou seja, a menor importância atribuída pelo respondente a um tópico ou questão. 
ciais/políticas/culturais realmente representam uma ameaça às suas empresas (ver tabela 30 ).

\section{Estrutura e Estratégia}

\section{(A) - Amostra Geral}

Somente $20 \%$ desses respondentes disseram que a distribuição do planejamento dos programas de responsabilidade social, por toda a organização, é uniforme em todos os níveis de suas empresas; $70 \%$ sentiam que esse planejamento estava concentrado nos escalões superiores de suas empresas (ver tabela 9). Tendo ou não ocorrido mudanças estruturais em suas empresas, resultantes da implantação dos programas de responsabilidade social selecionados, somente $14 \%$ desta amostra indicaram que praticamente não houve mudanças estruturais (grau 1) resultantes da contribuição à educação e ao desenvolvimento de recursos humanos, saúde e prestação de serviços fora das suas empresas. As respostas mais dignas de nota são as que obtiveram de quatro a cinco graus por pelo menos $9 \%$ dos respondentes e elas se referem a:

1. segurança da fábrica e dos empregados e

2. educação e desenvolvimento de recursos humanos para os empregados de suas empresas (conforme tabela 10).

\section{(B) - Amostra Focalizada}

As dimensões da teoria organizacional que requerem claramente mais planejamento nos programas de responsabilidade social das subsidiárias no exterior, tais como relatadas pelos escritórios da matriz e do exterior, são o impacto do meio ambiente externo, tecnologia da subsidiária, e o tamanho da subsidiária (ver tabela 21). Das questões selecionadas de programas de responsabilidade social, as que mais exercem influência sobre as mudanças organizacionais são a segurança das fábricas e empregados, juntamente com a saúde e prestação de serviços e desenvolvimento de recursos humanos e educação para os empregados da empresa (ver tabela 23).

\section{Implementação e impacto da responsabilidade social}

\section{(A) - Amostra Geral}

Embora somente $45 \%$ desses respondentes achem que a implementação da responsabilidade social de suas empresas tenha sido moderada, de acordo com os planos adotados a nível da matriz, outros $45 \%$ acreditam que ela tenha sido grande ou muito grande (ver tabela 11). Os orçamentos parecem estar compatíveis com os custos, de acordo com $75 \%$ dos participantes (ver tabela 13); não é possível, entretanto, determinar por esses dados se os orçamentos foram ou não adequados, já que somente $5 \%$ dos participantes indicaram que os custos excederam em muito a importância dos orçamentos (ver tabela 13).

No que diz respeito à eficácia dos programas de responsabilidade social de suas empresas em termos de custo/benefício, benefício social geral, moral dos empregados, atingimento de metas globais da corporação e atendimento a expectativas de grupos correlatos*, os seguintes resultados foram encontrados: $15 \%$ dos respondentes colocaram custo/benefício nas categorias de eficaz e moderadamente eficaz; $13 \%$ colocaram o benefício social geral nas categorias eficaz e muito eficaz; $16 \%$ classificaram o moral dos empregados nas categorias eficaz e muito eficaz; e $11 \%$ colocaram na categoria eficaz: (1) o êxito em alcançar as metas globais da empresa, e (2) o atendimento aos objetivos de grupos correlatos. $\mathrm{O}$ moral dos empregados foi considerado o fator de maior importância entre as respostas (ver tabela 14).

\section{(B) - Amostra Focalizada}

Mais de $75 \%$ dos respondentes indicaram que os programas de responsabilidade social de suas empresas tiveram implementação de moderada a muito grande, de acordo com os planos adotados (ver tabela 24). Em entrevistas pessoais foi possível constatar que os executivos sentiam que a implementação era feita de modo contínuo e com bons procedimentos de acompanhamento. De acordo com alguns dos entrevistados, tal implementação estava completamente integrada aos programas globais de suas empresas.

Cerca de $42 \%$ dos respondentes relataram que suas empresas maximizam os resultados favoráveis de programas de responsabilidade social em uma base média, querendo dizer que provavelmente haveria espaço para melhorias por parte de outras empresas da amostra, ou que al-

\footnotetext{
* Nota da Redaçāo: No original, constituency objectives; trata-se de objetivos de grupos que não participam da direção da empresa, mas com ela têm relações de interdependência: fornecedores, consumidores, acionistas. Ex.: expectativa de retorno sobre o investimento que os acionistas têm, mesmo que reconheçam a necessidade de programas de responsabilidade social na empresa.
} 
gumas empresas contentavam-se com resultados satisfatórios; isto, apesar de $12 \%$ dos participantes terem dito que a maximização dos resultados é "muito grande" (conforme tabela 26). No que tange à equiparação de custos e orçamentos dos programas de responsabilidade social, $66 \%$ dos participantes relataram que os valores dos orçamentos aproximaram-se dos custos (ver tabela 27). Em entrevistas com executivos da matriz, quase todos acreditam que os programas de responsabilidade social são eficazes em termos de custo.

Com relação à eficácia dos programas de responsabilidade social de suas companhias, considerando fatores selecionados, $9 \%$ dos respondentes colocaram o custo/benefício nas categorias de eficaz e muito eficaz; $7 \%$ colocaram o benefício social geral nas categorias eficaz e muito eficaz; $15 \%$ colocaram o moral dos empregados nas categorias eficaz e muito eficaz; $8 \%$ colocaram o êxito em alcançar as metas globais da corporação na categoria eficaz; e 6\% colocaram o êxito em alcançar os objetivos de grupos correlatos na categoria eficaz. $\mathrm{O}$ moral dos empregados recebeu o mais alto grau entre as respostas (ver tabela 28).

\section{Técnicas de avaliação de programas de responsabilidade social}

\section{(A) - Amostra Geral}

As impressões dos respondentes sobre os níveis nos quais os programas de responsabilidade social são avaliados variaram. Baseando-se em respostas múltiplas, das quais 120 era o número máximo, $28 \%$ relataram o seguinte: $12 \%$ disseram que as avaliações são feitas nas matrizes das empresas; $10 \%$ afirmaram serem executadas pela alta cúpula das subsidiárias; $6 \%$ a nível de diretoria. Uma parte relativamente pequena da avaliação foi relatada como sendo feita em todos os níveis dentro da estrutura hierárquica da MNC (conforme tabela 12). A monitoração dos programas de responsabilidade social dos concorrentes, por sua vez, revelou-se pequena (conforme tabela 15).

\section{(B) - Amostra Focalizada}

Com relação à existência de critérios para mensurar programas de responsabilidade social, a maioria dos respondentes disse que não os havia ou que estava pensando em estabelecê-los, apesar de $39 \%$ das respostas a esta questão terem sido positivas (conforme tabela 25). Ao fazer-se essa pergunta aos executivos das matrizes das empresas, poucos apresentaram técnicas de avaliação sig- nificativas usadas em suas MNCs, apesar de haver auditorias periódicas em locais operacionais.

\section{DISCUSSÃO}

Esta seção trata especificamente das cinco questões exploratórias enunciadas na introdução do texto, em função dos resultados da pesquisa expostos acima. Em alguns casos, torna-se útil apontar se a amostra geral ou a focalizada é pertinente ou não.

\section{Questão Exploratória 1}

Conquanto diversos níveis de métodos para o estabelecimento, implementação e avaliação de objetivos em programas de responsabilidade social estejam em evidência, provavelmente a sofisticação desses métodos é limitada, especialmente porque a evidência tende a mostrar poucos modelos formalizados, embora talvez não seja este o caso dos modelos projetados para programas de planejamento destinados ao pessoal interno das MNCs ${ }^{(62)}$. As empresas tendem a relacionar seus processos de responsabilidade social aos objetivos e ao planejamento estratégico global da corporação, isto é, não considerando a responsabilidade social como interesse isolado.

Assim, o planejamento de responsabilidade social é considerado crítico para se alcançarem as metas corporativas globais da empresa. Isso parece indicar que tais objetivos não são minimizados, e recebem atenção considerável por parte dos executivos da alta diretoria, conforme se mostrou na amostra focalizada. Há pouca consulta entre a matriz e suas subsidiárias no exterior, no estabelecimento dos objetivos de responsabilidade social.

De acordo com a amostra geral, os valores sociais e econômicos da alta diretoria parecem ter o maior peso no planejamento estratégico das MNCs. A experiência da administração e a sua capacidade de previsão continuam a ter um papel significativo no planejamento a longo prazo.

\section{Questão Exploratória 2}

A alta administração observa um aumento substancial na demanda dos seus públicos, no sentido de assumir programas de responsabilidade social, se bem que tais programas sejam estabelecidos mais como resultado de uma reação do que de uma iniciativa própria.

62. HAYDEL, Belmont F., Jr. Op. cit. 
O grupo empregados/sindicatos de trabaIhadores apresenta as maiores exigências. Além disso, os requisitos dos governos nos países da matriz e das subsidiárias freqüentemente atuam como meios de pressão. Aparentemente, observando-se a amostra focalizada, as MNCs reagem a posteriori, ou como uma tática de sobrevivência às demandas sociais de seus públicos. Esse ponto de vista parece coincidir com os de Drucker e de Ansoff ${ }^{(63)}$. Poucas firmas sentem alguma ameaça séria a sua existência, resultante do ambiente social, político e cultural.

\section{Questão Exploratória 3}

Algumas empresas iniciam programas relevantes de responsabilidade social por diversos motivos: o mais óbvio parece ser uma reação aos grupos trabalhistas, agências governamentais e concorrentes. As MNCs assumem liderança firme no planejamento da responsabilidade social interna, especialmente quando a segurança e a saúde dos empregados estão em jogo.

Conquanto a estrutura organizacional tenha se mostrado pouco afetada pelos processos de responsabilidade social interna (o que apóia o ponto de vista exposto em Corporate External Affairs: Blueprint for Survival ${ }^{(6)} \mathrm{em}$ alguns casos isolados (não averiguados nesta pesquisa) podem ocorrer reformulações estruturais significativas ${ }^{(65)}$. Qualquer que seja a estrutura projetada, a implementação parece ocorrer continuamente, de acordo com os planos adotados, representando um grau positivo de implementação, ao menos para certo pessoal interno. Nenhum julgamento pode ser feito, com base nessa conclusão, sobre a satisfação gerada por tal implementação. As questões de programas que mais influenciam as mudanças organizacionais são as de segurança dos empregados nas operações da fábrica.

As técnicas de avaliação parecem ser o ponto mais fraco do processo de administração estratégica. Elas podem se limitar à revisão da distribuição e utilização de fundos e à análise de custo/benefício. Ocorrem auditorias periódicas nos locais de operação, enquanto o desenvolvimento de critérios ainda está surgindo. A maior parte da avaliação é feita nas matrizes, enquanto que a administração nas subsidiárias também torna obrigatória a avaliação.

\section{Questão Exploratória 4}

Tudo o que as MNCs fazem com seriedade para os seus públicos dependentes é considerado bom negócio( $\left.{ }^{(6)}\right)$ e, portanto, lucrativo. Neste caso, a lucratividade também pode ser interpretada no sentido econômico, bem como o contexto mais amplo de satisfação do consumidor e a aprovação pública do comportamento da empresa, concordando-se com Drucker e o interesse aparente por parte da Comissão para o Desenvolvimento Econômico, em seu relatório sobre Responsabilidades Sociais das grandes empresas ${ }^{(6)}$. As empresas revelam uma relação de custo/benefício favorável, bem como equiparação dos fundos orçamentários com os custos, quando essas condições se relacionam ao planejamento e à implementação de responsabilidade social. $\mathrm{Na}$ amostra focalizada observa-se uma indicação clara de, pelo menos, uma intenção de maximizar os resultados dos seus programas de responsabilidade social, embora com implicações de que muitas empresas se contentam com resultados satisfatórios, dando, assim, crédito à teoria de Simon ${ }^{(68)}$. Isto apesar de as incertezas do meio ambiente serem causa de irregularidade dos lucros, como se registrou na amostra focalizada.

\section{Questão Exploratória 5}

A resposta a este assunto emerge de uma revisão dos quatro tópicos acima. Na melhor das hipóteses, pode-se concluir que algumas ações de responsabilidade social, enquanto forma de tecnologia, influenciam processos organizacionais de pesquisa, aprendizado e decisão ${ }^{(6)}$ sobre programas e questões de responsabilidade social. No entanto, a alta administração pouco conhece sobre esse fenômeno na responsabilidade social.

63. DRUCKER, Peter F. The Practice of Management. Op. cit.; ANSOFF, H. Igor. Op. cit.

\section{BODDEWYN, Jean J. Op. cit.}

65. Conforme apresentado por: CHANDLER, Alfred E. Op. cit.; PRESTON, Lee E. "Strategy - Structure - Performance: A Framework for Organizational/Environment Analysis". Op. cit: e STOPFORD, John M. \& WELLS, Louis T., Jr. Op. cit.

66. DRUCKER, Peter F. The Practice of Management. Op. cit.; SIMON, Herbert A. "On the Concept of Organizational Goals".Op. cit.; ANSOFF, H. Igor. Op. cit.

67. COMMITTEE FOR ECONOMIC DEVELOPMENT. Op. cit.

68. SIMON, Herbert A. "Administrative Decision Making".In: Public Administration Rewiew. March 1965, pp. 31.37.

69. THOMPSON, James D. Op. cit. 
Pelo menos existe uma percepção significativa dando apoio à necessidade de diferentes espécies de processos de administração estratégica de programas de responsabilidade social, quando comparada à requerida para tecnologias de produção/marketing e outras de cunho econômico. Tal fato parece apoiar a teoria de Thompson ${ }^{(70)}$.

\section{CONCLUSÃO}

A pesquisa apóia os achados de Steiner \& Steiner ${ }^{(7)}$, segundo os quais, cada vez mais membros da alta administração estão assumindo responsabilidade pelo estabelecimento de políticas sociais para suas empresas que parecem influenciar respostas adequadas às transformações de seu meio ambiente. Há fundos sendo aplicados em projetos sociais para parte do pessoal interno, notavelmente aquele selecionado neste estudo. Talvez a causa principal do envolvimento da empresa provenha da conscientização cada vez maior a favor de projetos sociais e do fato de algumas MNCs acreditarem que tal envolvimento seja crítico para atingirem suas metas globais. Essa tendência provavelmente continuará.

Descobertas referentes ao uso de modelos de administração estratégica demonstram claramente que a maioria dos executivos não acredita que suas empresas utilizem quaisquer modelos sistematicamente projetados para seus programas de responsabilidade social. O pesquisador acredita que tais descobertas possam ser limitadas pela compreensão dos respondentes sobre o que constitui um modelo.

As MNCs levam seriamente em consideração o desenvolvimento e a implementação de programas em benefício do seu pessoal interno, em três áreas específicas, a saber, a segurança dos empregados e das instalações fabris, o desenvolvimento educacional e dos recursos humanos e a assistência médica para seus empregados. A implementação pode variar de acordo com o tipo de programa, mas os fatos indicam que os recursos são empenhados, se bem que neste trabalho não se julgue se os recursos são ou não adequados. Como se sabe que o atingimento das metas da empresa nas áreas econômicas tradicionais é considerado mais significativo, os programas de responsabilidade social das MNCs podem sofrer um atraso com relação a outros programas da empresa, notadamente aqueles de produção e marketing.

Considerando-se que as políticas sociais empresariais são relativamente recentes, é preciso conhecer-se mais sobre a eficácia dos programas de responsabilidade social. Atualmente, há pouca evidência conclusiva disponível. Embora as des- cobertas mostrem resultados favoráveis, pode ser difícil quantificá-los. Esta pesquisa não apresenta resultados quantificáveis, mas, sim, uma abordagem conceitual do problema. Muito pouco está sendo feito pelos líderes das empresas em termos de avaliação real.

Conclui-se que a alta administração sente algumas ameaças por parte dos ambientes externo e interno, que tendem a forçar mudanças em seu processo de administração estratégica de programas de responsabilidade social. No entanto, é pouco significativo o número dos que sentem ameaças importantes e fica pouco claro até que ponto, ou de que forma tais mudanças podem ocorrer como resultados de ameaças. Já que a maior ameaça provém dos grupos de empregados/sindicatos de trabalhadores, o planejamento estratégico de programas de responsabilidade social que afetam o bem estar desses grupos provavelmente pareceria sofrer mudanças ditadas pelos interesses desses grupos.

Neste trabalho, embora a discussão dos elementos selecionados do processo de administração estratégica não proporcione evidência conclusiva a favor de programas de responsabilidade social, pode fornecer um enquadramento para a análise de outras questões e problemas e para o desenvolvimento de atividades e eventos em tais programas. Em sentido mais amplo, os administradores de MNCs tendem a permitir a tomada de decisões nos programas de responsabilidade social, mesmo que pouco sofisticados, mas que se baseiem mais na ação do que na análise crítica. Os administradores parecem encurtar os processos de administração estratégica quando constrangidos pelos custos e, talvez, por outras considerações financeiras.

$\mathrm{O}$ pesquisador acredita que existe lugar para programação integrada sócio-econômica dentro do comportamento de empresas internacionais, contanto que a parcela de responsabilidade social não seja interpretada como sendo inconsistente com a obtenção das metas relacionadas à tecnologia básica da empresa. Este ponto de vista pode coincidir com os trabalhos de Steiner \& Steiner e Drucker ${ }^{(72)}$, entre outros.

$\mathrm{O}$ pesquisador sugere cautela quanto à aceitação dos resultados deste trabalho como conclusivos, devido à base e campo de atuação limitados deste estudo, ou seja, um número pequeno

70. Idem, ibidem.

71. STEINER, George A. \& STEINER, John F. Op. cit.

72. Idem, ibidem; DRUCKER, Peter F. The Practice of Management. Op. cit. 
de empresas dentro de um determinado levantamento de campo. As discussões limitam-se à revisão do material colhido em quatro empresas selecionadas (amostra focalizada) e em um grupo de 18 empresas diversificadas (amostra geral), sendo este um outro fator que limita os resultados. Além disso, todas as empresas das amostras eram MNCs dos EUA e, portanto, podem apresentar uma tendência peculiar nos resultados. Os resultados e análises devem ser considerados como tentativas. Amostras mais amplas recolheriam maiores informações para o estabelecimento de bases mais amplas, dando maior validade aos resultados. Entretanto, este estudo pelo menos dá crédito à existência de interesses por parte das MNCs dos EUA no planejamento da responsabilidade social.

Existem boas razões para sugerir a feitura de mais pesquisas do planejamento estratégico dos programas da responsabilidade social das MNCs ligados tanto ao meio ambiente interno como ao externo. Sabe-se muito pouco sobre o planejamento da responsabilidade social nas MNCs. Tanto a pesquisa descritiva quanto a normativa parecem ser necessárias, envolvendo trabalho de campo e até mesmo em ambientes sob condições controladas, sempre que possível. Estudos de maior magnitude, isto é, consistindo de amostras com um número maior de empresas e projetos serviriam a um propósito mais útil, dada a suposição de que os resultados teriam aplicação mais universal. A pesquisa poderá dar mais ênfase ao pessoal interno e a estudos de caso de processos de administração estratégica de responsabilidade social. Estudos rigorosos, particularmente de teste de hipóteses, seriam mais conclusivos, mas não devem ser realizados em detrimento das análises descritivas. Estudos comparativos serviriam para ajudar as MNCs a entenderem os usos de diferentes métodos de administração estratégica, para que as empresas pudessem empreender ações corretivas ou imitativas, conforme o caso.

A implementação e a avaliação são elementos pertinentes do modelo da administração estratégica que parecem ser negligenciados do ponto de vista da pesquisa. Esta pesquisa indica negligência e falta de clareza nas práticas de implementação e avaliação de programas de responsabilidade social por parte das MNCs. Além disso, não se sabe quase nada sobre a correlação entre lucros e programas de responsabilidade social nas MNCs. Pesquisas empíricas nesta área lançariam alguma luz sobre a questão exploratória 4 deste trabalho.

Concluindo, a maioria dos tópicos apresentados neste trabalho representa apenas uma ponta do iceberg que envolve a administração estratégica da responsabilidade social nas MNCs. Esta discussão representa um resumo dos resultados de um volume maior de informações (não apresentado aqui) dentro do contexto de uma pesquisa limitada, que poderá incentivar pesquisas futuras em áreas semelhantes. Também se presta a demonstrar os numerosos problemas de estratégia que são enfrentados pelas MNCs, alguns dos quais se encontram no planejamento de programas de responsabilidade social. São necessários, portanto, mais estudos inquisitivos para se compreender e tornar mais significativo este extraordinário conjunto de fenômenos.]
ABSTRACT: This research presents an analysis of top management's perception in U.S. MNCs of corporate social responsibility programs, from a general survey of 18 home offices (29 respondents) and a focus survey of four selected firms (33 respondents, 17 from home and 16 from overseas). The firms figure among FORTUNE 500, each with annual sales exceeding US\$ one billion, in manufacturing, processing, and extractive sectors. The material focuses on MNCs decision-making process. Data were collected during 1982-1983. Some major findings are: strategic management of social responsibility programs for MNCs internal publics is found, although models are not very systematic; resources are committed, although somewhat constrained due to costs considerations; such programs lay behind those in marketing and production; threats from external and internal environments exert changes on strategic management processes, the biggest coming from employees and labor groups; among others.

KEY WORDS: corporate social responsibility, environment, MNCs, social responsibility, social responsibility programs, strategic management, strategic planning, U.S. multinational corporations. 
TABELAS

\section{A AMOSTRA GERAL}

TABELA 1: Consultas entre matrizes e filiais no exterior na formulação de programas de responsabilidade social

\begin{tabular}{lccccrrr}
\hline \multicolumn{1}{c}{ TERMOS RELATIVOS } \\
\hline & nunca & raramente & ocasionalmente & freqüentemente & sempre & n. r. & Total \\
\hline $\begin{array}{l}\text { Total } \\
\text { n. } r .\end{array}$ & 5 & 25 & 35 & 25 & 10 & 0 & 100 \\
Total & & & & & 0 & 100 \\
\hline
\end{tabular}

$\mathrm{N}=20$

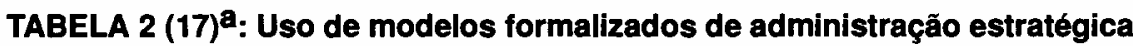
para determinação de objetivos de responsabilidade social

\begin{tabular}{lccrr}
\hline & \multicolumn{2}{c}{ TERMOS RELATIVOS } & pensando em usar & Total \\
\hline & $\operatorname{sim}$ & não & 05 & 100 \\
\hline $\begin{array}{l}\text { Total } \\
\text { n. } r \text {. }\end{array}$ & 10 & 85 & 0 \\
Total & & & 100 \\
\hline
\end{tabular}

$\mathrm{N}=20$

$a=0$ número entre parênteses indica sempre a tabela correspondente na outra amostra.

TABELA 3 (18) a: Relação entre o planejamento de responsabilidade social e 0 planejamento estratégico global da corporacão

\begin{tabular}{lcccrrr}
\hline & \multicolumn{3}{c}{ TERMOS RELATIVOS } \\
\hline & nenhuma & pequena & moderada & grande & total & Total \\
\hline Total & 10 & 30 & 30 & 20 & 10 & 100 \\
n. $r$. & & & & & 0 \\
Total & & & & & 100 \\
\hline r & & & & &
\end{tabular}

TABELA 4 (19) : Importância dos objetivos de responsabilidade social da empresa no atingimento de metas de alcance mundial da corporação

\begin{tabular}{|c|c|c|c|c|c|c|}
\hline \multicolumn{7}{|c|}{ TERMOS RELATIVOS } \\
\hline & nula & pequena & moderada & grande & muito grande & Total \\
\hline $\begin{array}{l}\text { Total } \\
\text { n. r. } \\
\text { Total }\end{array}$ & 0 & 20 & 30 & 40 & 10 & $\begin{array}{r}100 \\
0 \\
100\end{array}$ \\
\hline
\end{tabular}


TABELA 5: Impacto dos valores da cúpula

administrativa sobre o desenvolvimento do planejamento estratégico nas matrizes

\begin{tabular}{|c|c|c|c|c|c|c|}
\hline \multicolumn{7}{|c|}{ TERMOS RELATIVOS } \\
\hline Valores & 1 & 2 & 3 & 4 & 5 & Total \\
\hline Sociais & 1 & 0 & 4 & 7 & 5 & 16 \\
\hline Econômicos & 0 & 1 & 3 & 5 & 8 & 16 \\
\hline Estéticos & 4 & 6 & 6 & 0 & 1 & 16 \\
\hline Políticos & 5 & 3 & 3 & 1 & 3 & 15 \\
\hline Religiosos & 8 & 3 & 3 & 1 & 1 & 15 \\
\hline Teóricos & 3 & 6 & 3 & 2 & 3 & 15 \\
\hline Total & 20 & 19 & 21 & 15 & 20 & 98 \\
\hline n. r. & & & & & & 2 \\
\hline Total & & & & & & 100 \\
\hline
\end{tabular}

$N=120$ (6 valores $\times 20$ respondentes)

Obs.: Nesta tabela e nas demais em que se empregam escalas de 1 a 5, o grau 1 representa sempre o menor impacto, ou seja, a menor importância atribuída pelos respondentes a um tópico ou questão.

TABELA 6: Peso dos critérios administrativos no desenvolvimento do planejamento estratégico

\begin{tabular}{lrrrrrr}
\hline & \multicolumn{7}{c}{ TERMOS RELATIVOS } & & \\
\hline Gritérios & 1 & 2 & 3 & 4 & 5 & Total \\
\hline $\begin{array}{l}\text { Experiência gerencial } \\
\text { Intuição/capacidade }\end{array}$ & 0 & 0 & 1 & 9 & 15 & 25 \\
de previsão gerencial & 0 & 1 & 5 & 8 & 11 & 25 \\
Habilidade gerencial & 0 & 1 & 10 & 8 & 6 & 25 \\
Valores gerenciais & 0 & 0 & 8 & 14 & 4 & 25 \\
Total & 0 & 2 & 23 & 37 & 36 & 100 \\
n. r. & & & & & & 0 \\
Total & & & & & & 100 \\
\hline
\end{tabular}

$\mathrm{N}=80$ (4 critérios $\times 20$ respondentes) 
TABELA 7 (22) a: Grau de influência dos grupos de interesse na determinação dos programas de responsabilidade social da empresa

\begin{tabular}{|c|c|c|c|c|c|c|}
\hline \multicolumn{7}{|c|}{ TERMOS RELATIVOS } \\
\hline $\begin{array}{l}\text { Grupos } \\
\text { de interesse }\end{array}$ & 1 & 2 & 3 & 4 & 5 & Total \\
\hline Consumidores & 2 & 3 & 2 & 6 & 4 & 16 \\
\hline Fornecedores & 5 & 7 & 2 & 3 & 1 & 16 \\
\hline Concorrentes & 2 & 3 & 4 & 8 & 1 & 16 \\
\hline Empregados/sindicatos & 0 & 0 & 4 & 9 & 3 & 15 \\
\hline Governos hospedeiros & 1 & 1 & 3 & 7 & 4 & 15 \\
\hline $\begin{array}{l}\text { Governos nos países } \\
\text { das matrizes }\end{array}$ & 0 & 3 & 2 & 8 & 4 & 16 \\
\hline Total & 9 & 16 & 16 & 39 & 16 & 98 \\
\hline n. r. & & & & & & 1 \\
\hline Total & & & & & & 100 \\
\hline
\end{tabular}

$N=120$ (6 grupos de interesse $\times 20$ respondentes)

TABELA 8: Liderança de empresa no planejamento de itens selecionados de responsabilidade social

\begin{tabular}{|c|c|c|c|c|c|c|}
\hline \multicolumn{7}{|c|}{ TERMOS RELATIVOS } \\
\hline Itens Graus & 1 & 2 & 3 & 4 & 5 & Total \\
\hline \multicolumn{7}{|l|}{ Segurança da planta } \\
\hline e dos funcionários & 1 & 0 & 5 & 6 & 7 & 19 \\
\hline \multicolumn{7}{|l|}{ Educ.e Desenv.de RH } \\
\hline para funcionários da empresa & 0 & 4 & 6 & 6 & 3 & 19 \\
\hline \multicolumn{7}{|l|}{ Educ.e Desenv.de RH } \\
\hline fora da empresa & 0 & 5 & 6 & 2 & 4 & 17 \\
\hline Assist.médica para & & & & & & \\
\hline funcionários da empresa & 0 & 0 & 4 & 6 & 9 & 19 \\
\hline \multicolumn{7}{|l|}{ Assist.médica } \\
\hline fora da empresa & 0 & 2 & 10 & 1 & 4 & 17 \\
\hline Total & 1 & 11 & 31 & 21 & 27 & 91 \\
\hline n. $r$. & & & & & & 9 \\
\hline Total & & & & & & 100 \\
\hline
\end{tabular}

$N=100$ (5 itens $\times 20$ respondentes) 
TABELA 9: Distribuição do planejamento de programas de responsabilidade social por toda a organização

\begin{tabular}{|c|c|c|c|c|c|c|}
\hline \multicolumn{7}{|c|}{ TERMOS RELATIVOS } \\
\hline & $\begin{array}{c}\text { alta } \\
\text { cúpula }\end{array}$ & $\begin{array}{l}\text { em direção } \\
\text { à alta cúpula }\end{array}$ & $\begin{array}{c}\text { igual em } \\
\text { todos os níveis }\end{array}$ & $\begin{array}{c}\text { em direção } \\
\text { à base }\end{array}$ & $\begin{array}{c}\text { toda } \\
\text { descentralizada }\end{array}$ & Total \\
\hline $\begin{array}{l}\text { Total } \\
\text { n. r. } \\
\text { Total }\end{array}$ & 20 & 50 & 20 & 0 & 10 & $\begin{array}{r}100 \\
0 \\
100\end{array}$ \\
\hline
\end{tabular}

$\mathrm{N}=20$

TABELA $10(23)^{\mathrm{a}}$ : Grau de mudanças na estrutura organizacional resultantes de programas selecionados de responsabilidade social

\begin{tabular}{|c|c|c|c|c|c|c|}
\hline \multicolumn{7}{|c|}{ TERMOS RELATIVOS } \\
\hline Graus & 1 & 2 & 3 & 4 & 5 & Total \\
\hline \multicolumn{7}{|l|}{ Segurança da planta } \\
\hline e dos funcionários & 5 & 2 & 3 & 4 & 5 & 19 \\
\hline \multicolumn{7}{|l|}{ Educ.e Desenv.de RH } \\
\hline para funcionários da empresa & 2 & 3 & 4 & 5 & 5 & 19 \\
\hline \multicolumn{7}{|l|}{ Educ.e Desenv.de RH } \\
\hline fora da empresa & 7 & 2 & 6 & 3 & 0 & 18 \\
\hline \multicolumn{7}{|l|}{ Assist.médica para } \\
\hline funcionários da empresa & 3 & 4 & 5 & 4 & 3 & 19 \\
\hline \multicolumn{7}{|l|}{ Assist.médica } \\
\hline fora da empresa & 7 & 5 & 4 & 0 & 2 & 18 \\
\hline Total & 24 & 16 & 22 & 16 & 15 & 93 \\
\hline n. r. & & & & & & 9 \\
\hline Total & & & & & & 100 \\
\hline
\end{tabular}

$\mathrm{N}=100$ (5 itens $\times 20$ respondentes)

TABELA 11 (24) ${ }^{a}$ : Extensão da implementação de programas de responsabilidade social de acordo com planos da empresa

\begin{tabular}{|c|c|c|c|c|c|c|}
\hline \multicolumn{7}{|c|}{ TERMOS RELATIVOS } \\
\hline & nenhuma & pequena & moderada & grande & muito grande & Total \\
\hline $\begin{array}{l}\text { Total } \\
\text { n. r. } \\
\text { Total }\end{array}$ & 5 & 0 & 45 & 30 & 15 & $\begin{array}{r}95 \\
5 \\
100\end{array}$ \\
\hline
\end{tabular}

$\mathrm{N}=20$ 
TABELA 12: Níveis de avaliação dentro da empresa dos programas de responsabilidade social

\begin{tabular}{lr}
\hline & TERMOS RELATIVOS \\
\hline & Total \\
\hline Unidades subsidiárias & 5 \\
Alta cúpula das subsidiárias & 10 \\
Escritórios regionais no exterior & 4 \\
Matriz & 12 \\
Diretoria & 6 \\
Todos os níveis acima & 2 \\
Total & 42 \\
n. r. & 58 \\
Total & 100 \\
\hline
\end{tabular}

$\mathrm{N}=120$ (6 níveis $\times 20$ respondentes)

TABELA $13(27)^{a}$ : Compatibilização entre custos e orçamentos nos programas de responsabilidade social

\begin{tabular}{lccccrr}
\hline \multicolumn{7}{c}{ TERMOS RELATIVOS } \\
\hline $\begin{array}{l}\text { orçamento muito } \\
\text { acima do custo }\end{array}$ & $\begin{array}{c}\text { orçamento } \\
\text { acima do custo }\end{array}$ & $\begin{array}{c}\text { orçamento } \\
\text { próximo do custo }\end{array}$ & $\begin{array}{c}\text { custo acima } \\
\text { do orçamento }\end{array}$ & $\begin{array}{c}\text { custo muito acima } \\
\text { do orçamento }\end{array}$ & Total \\
\hline $\begin{array}{l}\text { Total } \\
\text { n. } \mathrm{r} \text {. }\end{array}$ & 5 & 10 & 75 & 0 & 5 & 95 \\
Total & & & & & 5 \\
\hline $\mathrm{N}=20$ & & & & & & 100 \\
\hline
\end{tabular}

TABELA 14 (28) a : Eficácia dos programas de responsabilidade social da empresa, considerando fatores selecionados

\begin{tabular}{|c|c|c|c|c|c|c|}
\hline \multicolumn{7}{|c|}{ TERMOS RELATIVOS } \\
\hline Fator & $\begin{array}{c}\text { muito } \\
\text { ineficaz } \\
1\end{array}$ & $\begin{array}{c}\text { ineficaz } \\
2\end{array}$ & $\begin{array}{c}\text { moderadamente } \\
\text { eficaz } \\
3\end{array}$ & $\begin{array}{c}\text { eficaz } \\
4\end{array}$ & $\begin{array}{c}\text { muito } \\
\text { eficaz } \\
5\end{array}$ & Total \\
\hline Custo/benefício & 0 & 2 & 8 & 7 & 0 & 17 \\
\hline Benefício social geral & 0 & 0 & 6 & 11 & 2 & 19 \\
\hline Moral dos empregados & 0 & 0 & 3 & 13 & 3 & 19 \\
\hline $\begin{array}{l}\text { Atingimento de metas } \\
\text { principais da Cia. }\end{array}$ & 0 & 1 & 7 & 11 & 0 & 19 \\
\hline $\begin{array}{l}\text { Atendimento a expectativas } \\
\text { de grupos correlatos }\end{array}$ & 0 & 1 & 6 & 11 & 0 & 18 \\
\hline $\begin{array}{l}\text { Total } \\
\text { n. r. } \\
\text { Total }\end{array}$ & 0 & 4 & 30 & 53 & 5 & $\begin{array}{c}92 \\
7 \\
100\end{array}$ \\
\hline
\end{tabular}

$N=100$ ( 5 fatores $\times 20$ respondentes) 
TABELA 15: Monitoração dos programas de responsabilidade social da concorrência

\begin{tabular}{lcccrrr}
\hline \multicolumn{7}{c}{ TERMOS RELATIVOS } \\
\hline & nenhuma & pequena & moderada & grande & muito grande & Total \\
\hline Total & 0 & 60 & 25 & 15 & 0 & 100 \\
n. $r$. & & & & & 0 \\
Total & & & & & 100 \\
\hline
\end{tabular}

$\mathrm{N}=20$

TABELA 16 (30)a: Ameaças do ambiente sócio-político-cultural à empresa

\begin{tabular}{|c|c|c|c|c|c|c|}
\hline & $\operatorname{sim}$ & não & às vezes & não sabe & não respondeu & Total \\
\hline $\begin{array}{l}\text { Total } \\
\text { n. r. } \\
\text { Total }\end{array}$ & 15 & 15 & 70 & 0 & 0 & $\begin{array}{r}100 \\
0 \\
100\end{array}$ \\
\hline
\end{tabular}

$\mathrm{N}=20$

\section{A AMOSTRA FOCALIZADA}

TABELA 17 (2) ${ }^{a}$ : Uso de modelos formalizados de administração estratégica para determinação de objetivos de responsabilidade social

\begin{tabular}{lcccr}
\hline & \multicolumn{3}{c}{ TERMOS RELATIVOS } & pensando em usar \\
\hline & sim & não & 0 & 97 \\
\hline Total & 21 & 75 & 3 \\
n. r. & & & & 100 \\
Total & & & & Total \\
\hline
\end{tabular}

$\mathrm{N}=33$

$\mathrm{a}=\mathrm{o}$ número entre parênteses indica sempre a tabela correspondente na outra amostra.

TABELA 18 (3) a: Relação entre o planejamento de responsabilidade social e o planejamento estratégico global da corporação

\begin{tabular}{|c|c|c|c|c|c|c|}
\hline \multicolumn{7}{|c|}{ TERMOS RELATIVOS } \\
\hline & nenhuma & pequena & moderada & grande & total & Total \\
\hline $\begin{array}{l}\text { Total } \\
\text { n. r. } \\
\text { Total }\end{array}$ & 21 & 18 & 24 & 24 & 9 & $\begin{array}{r}97 \\
3 \\
100\end{array}$ \\
\hline
\end{tabular}

$\mathrm{N}=33$ 
TABELA 19 (4) a : Importância dos objetlvos de responsabllidade social da empresa no atingimento de metas de alcance mundlal da corporação

\begin{tabular}{lcccrrr}
\hline \multicolumn{7}{c}{ TERMOS RELATIVOS } \\
\hline & nula & pequena & moderada & grande & muito grande & Total \\
\hline Total & 6 & 15 & 27 & 18 & 24 & 91 \\
$\mathrm{n} . \mathrm{r}$. & & & & & 9 \\
Total & & & & & 100 \\
\hline $\mathrm{N}=33$ & & & & &
\end{tabular}

TABELA 20: Reação da empresa a demandas sociais no mundo todo

\begin{tabular}{|c|c|c|c|c|}
\hline \multicolumn{5}{|c|}{ TERMOS RELATIVOS } \\
\hline & $\begin{array}{l}\text { reage à demanda } \\
\text { (a) }\end{array}$ & $\begin{array}{l}\text { usa planos pré-concebidos } \\
\text { (b) }\end{array}$ & (a) e (b) & Total \\
\hline $\begin{array}{l}\text { Total } \\
\text { n. r. } \\
\text { Total }\end{array}$ & 30 & 6 & 54 & $\begin{array}{r}91 \\
9 \\
100\end{array}$ \\
\hline
\end{tabular}

TABELA 21: Impacto de fatores organizacionals sobre o planejamento de programas de responsabilidade social em subsidiárias no exterlor

\begin{tabular}{|c|c|c|c|c|c|c|}
\hline \multicolumn{7}{|c|}{ TERMOS RELATIVOS } \\
\hline Dimensāo & 1 & 2 & 3 & 4 & 5 & Total \\
\hline Tamanho da subsidiária & 4 & 6 & 5 & 2 & 5 & 20 \\
\hline Estrutura da subsidiária & 5 & 7 & 4 & 3 & 2 & 20 \\
\hline Tecnologia da subsidiária & 5 & 3 & 4 & 5 & 4 & 19 \\
\hline Ambiente externo & 1 & 2 & 2 & 8 & 6 & 18 \\
\hline Outros & 0 & 0 & 3 & 0 & 4 & 6 \\
\hline Total & 14 & 18 & 17 & 16 & 19 & 86 \\
\hline n. r. & & & & & & 13 \\
\hline Total & & & & & & 100 \\
\hline
\end{tabular}

$N=165$ (5 dimensões $\times 33$ respondentes) 
TABELA 22 (7) ${ }^{\mathrm{a}}$ : Grau de influência dos grupos de interesse na determinaçáo dos programas de responsabilidade social da empresa

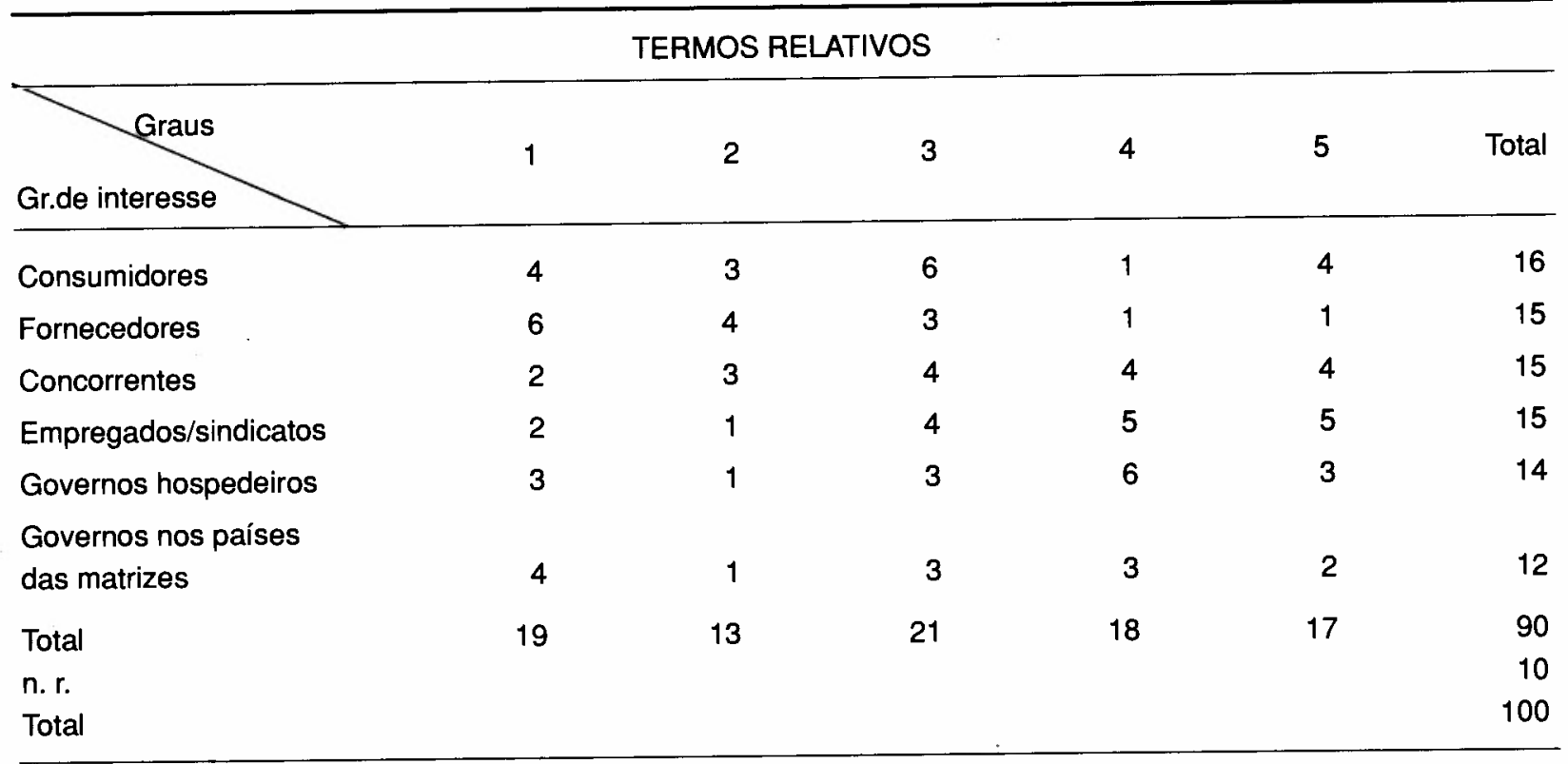

$\mathrm{N}=198$ (6 grupos de interesse $\times 33$ respondentes)

TABELA $23(10)^{a}$ : Grau de mudanças na estrutura organizacional resultantes de programas selecionados de responsabilidade social

\begin{tabular}{|c|c|c|c|c|c|c|}
\hline \multicolumn{7}{|c|}{ TERMOS RELATIVOS } \\
\hline Itens Graus & 1 & 2 & 3 & 4 & 5 & Total \\
\hline Segurança da planta & & & & & & \\
\hline e dos funcionários & 3 & 2 & 2 & 5 & 7 & 18 \\
\hline $\begin{array}{l}\text { Educ.e Desenv.de RH } \\
\text { para funcionários da empresa }\end{array}$ & 1 & 1 & 7 & 5 & 2 & 17 \\
\hline $\begin{array}{l}\text { Educ.e Desenv.de RH } \\
\text { forà da empresa }\end{array}$ & 6 & 5 & 4 & 1 & 1 & 16 \\
\hline $\begin{array}{l}\text { Assist.médica para } \\
\text { funcionários da empresa }\end{array}$ & 2 & 1 & 7 & 4 & 5 & 18 \\
\hline Assist.médica & & & & & & \\
\hline fora da empresa & 8 & 4 & 2 & 1 & 1 & 16 \\
\hline Total & 20 & 12 & 22 & 15 & 15 & 87 \\
\hline n. r. & & & & & & 13 \\
\hline Total & & & & & & 100 \\
\hline
\end{tabular}

$\mathrm{N}=165$ (5 itens $\times 33$ respondentes) 
TABELA 24 (11) ${ }^{a}$ : Extensão da implementação de programas de responsabilidade social de acordo com os planos da empresa

\begin{tabular}{lcccrrr}
\hline & & & \\
& nenhuma & pequena & moderada & grande & muito grande & Total \\
\hline Total & 9 & 6 & 21 & 33 & 24 & 94 \\
n. $r$. & & & & & 6 \\
Total & & & & & 100 \\
\hline
\end{tabular}

$\mathrm{N}=33$

TABELA 25: Estabelecimento de critérios nas matrizes e/ou filiais para mensurar programas de responsabilidade social

\section{TERMOS RELATIVOS}

\begin{tabular}{lcccrr}
\hline & sim & não & pensando em estabelecer & estabelecendo critérios & Total \\
\hline Total & 39 & 48 & 9 & 0 & 97 \\
n. r. & & & & 3 \\
Total & & & & 100 \\
\hline
\end{tabular}

$\mathrm{N}=33$

TABELA 26: Maximização dos resultados favoráveis dos programas de responsabilidade social pela empresa

\begin{tabular}{|c|c|c|c|c|c|c|}
\hline \multicolumn{7}{|c|}{ TERMOS RELATIVOS } \\
\hline & nula & pequena & média & grande & muito grande & Total \\
\hline $\begin{array}{l}\text { Total } \\
\text { n. } r \text {. } \\
\text { Total }\end{array}$ & 9 & 9 & 42 & 15 & 12 & $\begin{array}{r}88 \\
12 \\
100\end{array}$ \\
\hline
\end{tabular}

TABELA 27 (13) ${ }^{\text {: }}$ Compatibilização entre custos e orçamentos nos programas de responsabilidade social

\begin{tabular}{|c|c|c|c|c|c|c|}
\hline \multicolumn{7}{|c|}{ TERMOS RELATIVOS } \\
\hline & $\begin{array}{l}\text { orçamento } \\
\text { muito } \\
\text { acima do } \\
\text { custo }\end{array}$ & $\begin{array}{c}\text { orçamento } \\
\text { acima } \\
\text { do custo }\end{array}$ & $\begin{array}{c}\text { orçamento } \\
\text { próximo } \\
\text { do custo }\end{array}$ & $\begin{array}{c}\text { custo } \\
\text { acima } \\
\text { do orça- } \\
\text { çamento }\end{array}$ & $\begin{array}{c}\text { custo } \\
\text { muito } \\
\text { acima do } \\
\text { orçamento }\end{array}$ & Total \\
\hline $\begin{array}{l}\text { Total } \\
\text { n. r. } \\
\text { Total }\end{array}$ & 0 & 9 & 66 & 9 & 3 & $\begin{array}{r}88 \\
12 \\
100\end{array}$ \\
\hline
\end{tabular}


TABELA $28(14)^{a}$ : Eficácia dos programas de responsabilidade social da empresa, considerando fatores selecionados

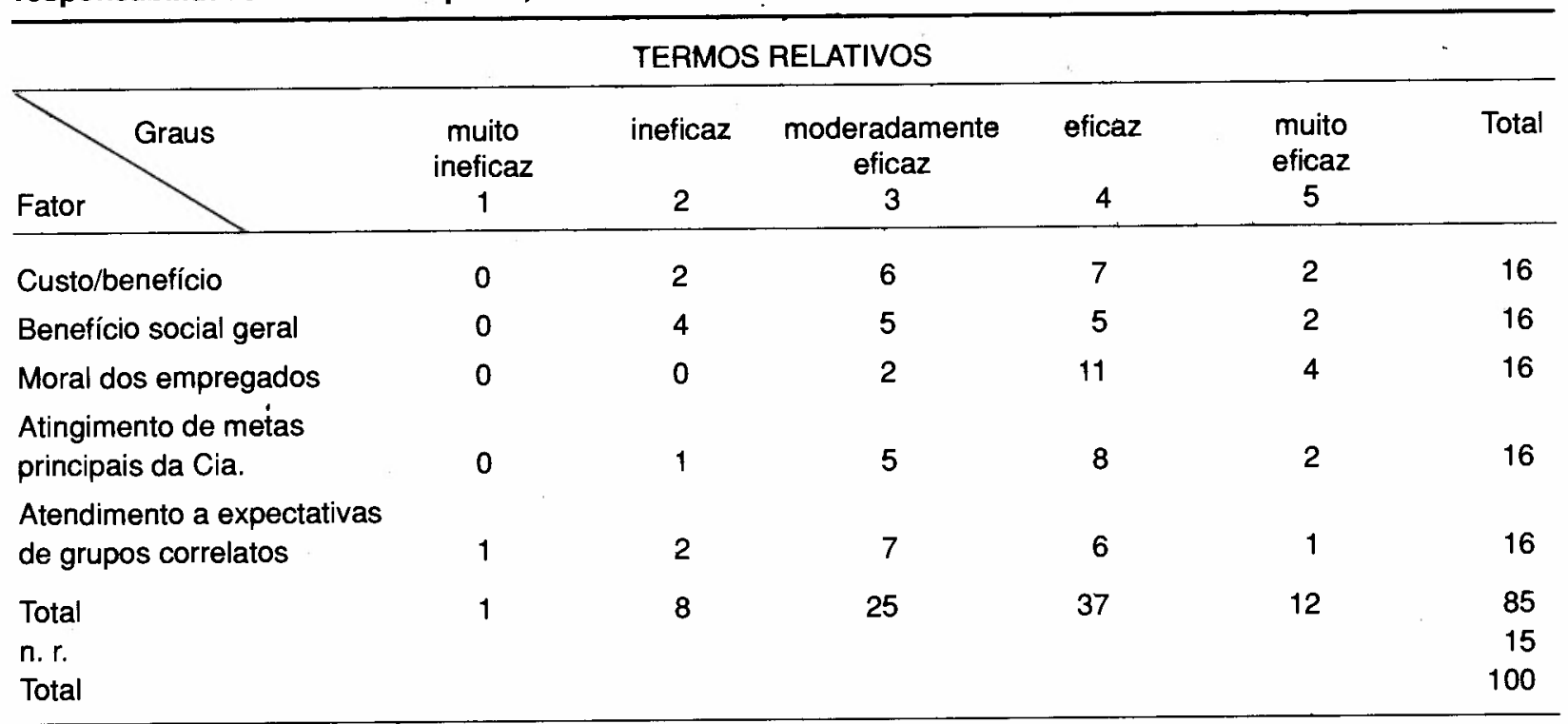

$N=165$ (5 fatores $\times 33$ respondentes)

TABELA 29: Extensão em que a incerteza afeta a regularidade do lucro

\begin{tabular}{lcccrrr}
\hline \multicolumn{7}{c}{ TERMOS RELATIVOS } \\
\hline & nula & pequena & moderada & grande & muito grande \\
\hline Total & 3 & 18 & 21 & 30 & 15 & Total \\
n. r. & & & & & 12 \\
Total & & & & 100 \\
\hline
\end{tabular}

$\mathrm{N}=33$

TABELA 30 (16) $^{\text {a: }}$ Ameaças do ambiente sócio-político-cultural à empresa

\begin{tabular}{|c|c|c|c|c|c|}
\hline \multicolumn{6}{|c|}{ TERMOS RELATIVOS } \\
\hline & sim & não & às vezes & não sabe & Total \\
\hline $\begin{array}{l}\text { Total } \\
\text { n. r. } \\
\text { Total }\end{array}$ & 21 & 15 & 45 & 6 & $\begin{array}{r}88 \\
12 \\
100\end{array}$ \\
\hline
\end{tabular}

$\mathrm{N}=33$ 